تقويم محتوى وأنشطة مناهج الاراسات الاجتماعية بالمرحلة الإعدادية في ضوء مهارات القرن الحادي والعشرين

بحث مقام ضمن متطلبات الحصول على درجة الماجستير في التربية (تخصص مناهج وطرق تدريس دراسات اجتماعية)

$$
\text { إعداد }
$$

ياسمين محمد صابر محمد أبو حسن

معلمة دراسات اجتماعية بمدرسة الإسلامية الإعادية بنات

\title{
تحت اشـراف
}

$$
\text { د/ محمد محمد حال }
$$

مدرس المناهج وطرق تدريس التاريخ

$$
\text { بكلية التربية- جامعة بورسعيد }
$$

أ. - مباس راغب علام

أستاذ المناهج وطرق تدريس الاراسات الاجتماعية بكلية التربية- جامعة بورسعيد 
تقويم محتوى وأنشطة مناهج الدراسات الاجتماعية بالمرحلة الإعدادية في ضوء مهارات القرن الحادي والعشرين

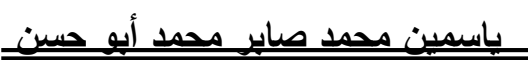

$$
\text { الملخص }
$$

يهذف البحث إلي:

- إعداد قائمة بمهارات القرن الحادي والعشرين اللازم توافرها في محتوى وأنثطة مناهج الاراسات الاجتماعية بالمرحلة الإعدادية.

- تقويم المحتوى والأنثطة التعليمية لمنهج الدارات بالعرات الاجتماعية بالصف الأول الإعدادى في ضوء مهارات القرن الحادي وإلعشرين.

واستخدمت الباحثة المنهج الوصفى، وقامت بإعداد قائمة ببعض مهارات القرن الحادي والعشرين

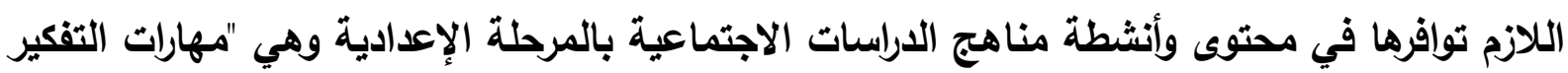

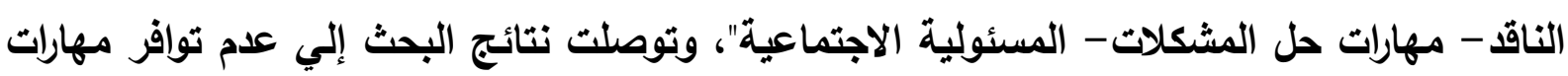

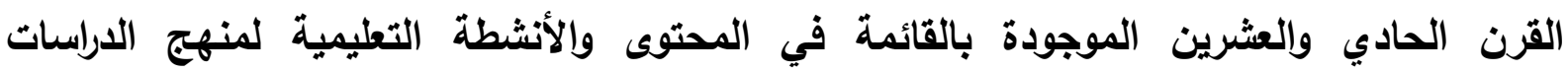
الاجتماعية بالصف الأول الإعدادى إلا بارجة ضئيلة. 
تقويم محتوى وأنثطة مناهج الدراسات الاجتماعية بالمرحلة الإعدادية في ضوء مهارات القرن الحادي والعشرين

\section{Abstract}

The research aims to:

- Preparing a list of the Twenty-First Century Skills that should exist in the Content and Activities for Social Studies curriculum of the preparatory stage.

- Evaluating the Content and Educational Activities for Social Studies Curriculum of the first preparatory grade in the light of the TwentyFirst Century Skills.

The researcher used the descriptive approach, and prepared a list of some of the Twenty- First Century Skills that should exist in the Content and Activities for Social Studies curriculum of the preparatory stage, these are: "Critical Thinking Skills, Problem-solving skills, Social Responsibility".

Results of the research led to : Non-availability of the Twenty-First Century Skills in the Content and Educational Activities for Social Studies Curriculum of the first preparatory grade except a minor degree. 
يشهر القرن الحادي والعشرين تحولاً واسع المدى في النظرة إلى التعليم بصفة عامة والنظرة إلى ولى

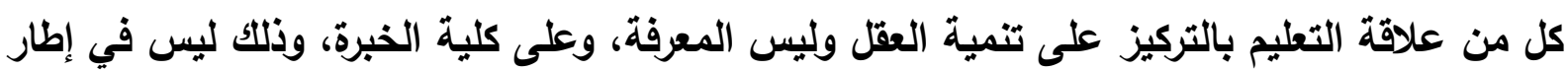

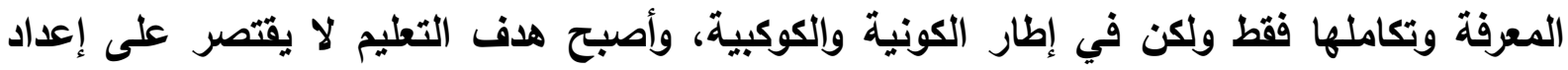

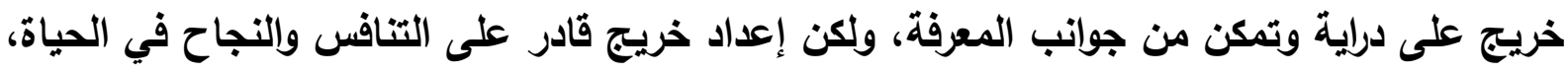
والعمل ليس على المستوى القومي فقط ولكن على على المستوى العالمي.

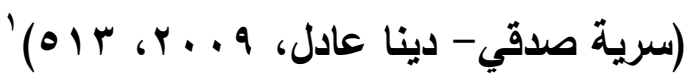

ومع حلول الألفية الثالثة يجب أن يمتلك التلاميذ مهارات على مستوي عالي تسمى مهارات تعلم

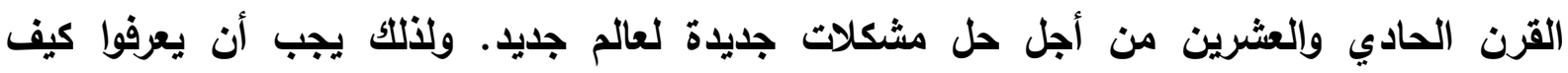

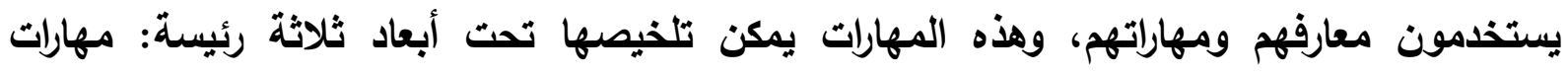

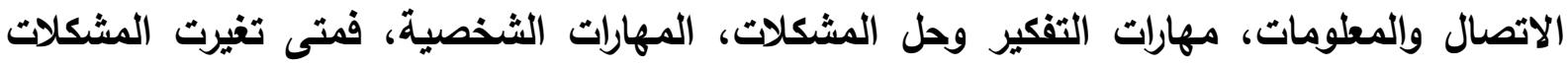
التعليمية تغيرت الحلول الشخصية لهذه المشكلات في الوقت نفسه. ولذاتلك يتطلب تحقيق أهداف

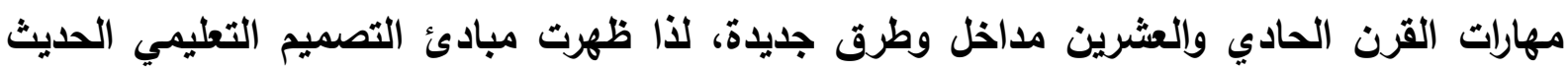
لتقابل احتياجات القرن الحادي والعشرين. (Sahin, 2009, 1464) فلم تعد تستطيع أساليب التعليم التقليدية مقابلة الاحتياجات التعليمية للمجتمع الحديث والتعادئ

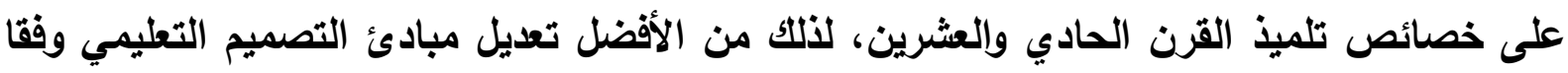
لمهارات القرن الحادي والعشرين. (Sahin, 2009, 1466) فالتلميذ يحتاج إلى تعلم المحتوى العلمي من خلال أمثلة وتطبيقات وخبرات من الحياة الحقيقية

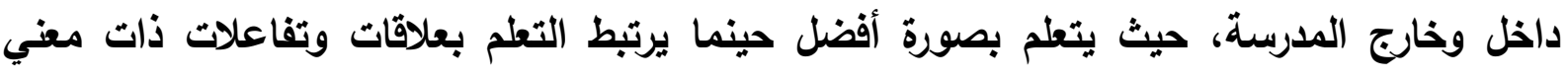

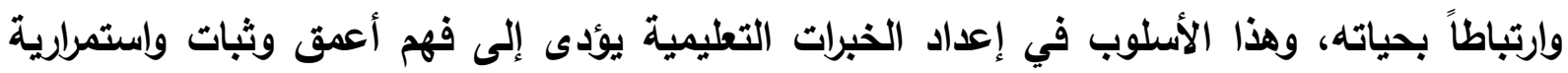

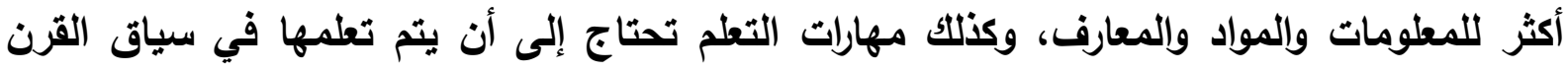

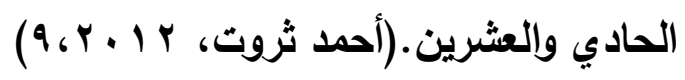
ولتحقيق منطلبات القرن الحادي والعشرين يجب على والى التلاميذ معرفة ما هو هو أكثر من المواد

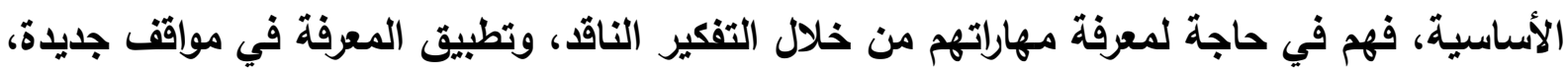

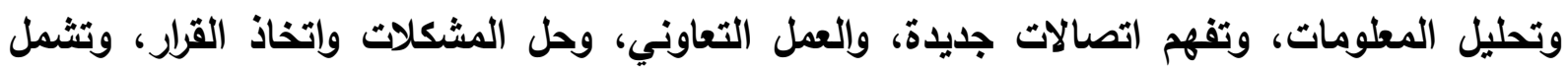
مهارات التعلم ثُلاث مهارات أساسية: 
information and technology skills المهارات المعوماتية والتكنولوجية information skills أ- مهارات المعرفة communication skills ب-مهارات الاتصال

thinking and problem solving skills r. مهارات التفكير وحل المشكلات

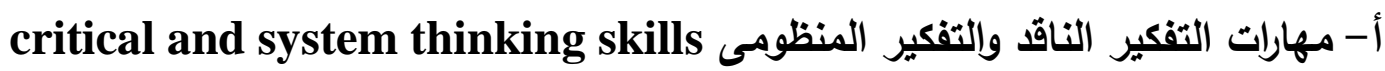

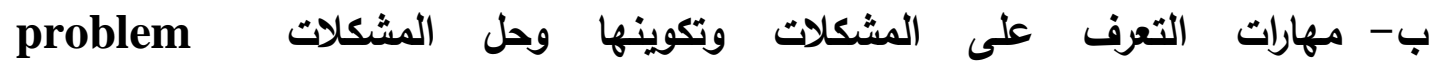
identification , formulation and solution creativity and intellectual ج-مهارات الإبداع وحب الاستطلاع العقلي (التأملي) curiosity

life and career skills المهارات الحياتية والمهنية interpersonal and collaborative skills أ- المهارات الثخصية والتعاونية ب- مهارات التوجه الذاتي self direction

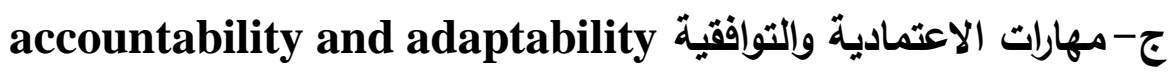
social responsibility المسئولية الاجتماعية

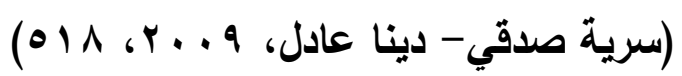

وهناك العديد من التحديات التي تواجه مجتمعنا العربي وهو يخطو نحو القرن الحادي والعشرين،

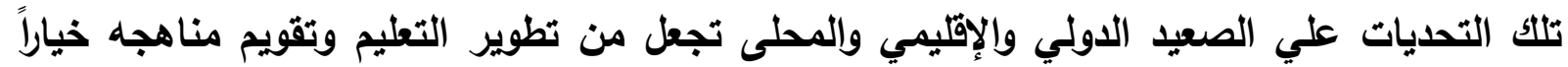

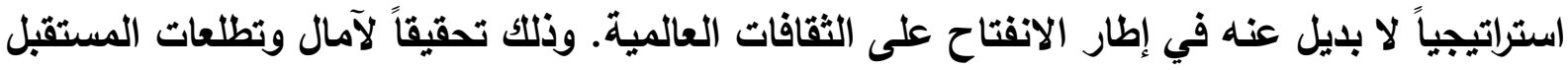
المنشودة والتمكن من مواكبة ما يحدث في العالم من تغيرات عصرية ومستقبلية في شتي المجالات.

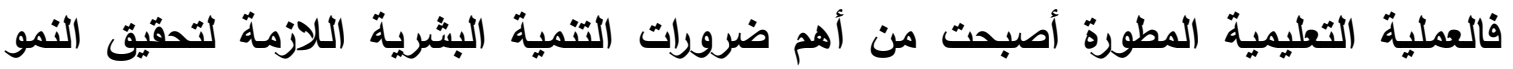
الثامل، الأمر الأي يتطلب التغير الثامل المستمر في فكر وثقافة أي مجتمع يسعى للتقدم وذلك لن لن

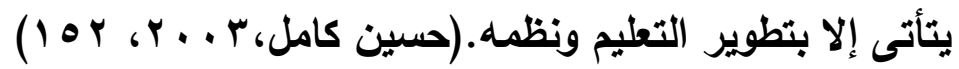

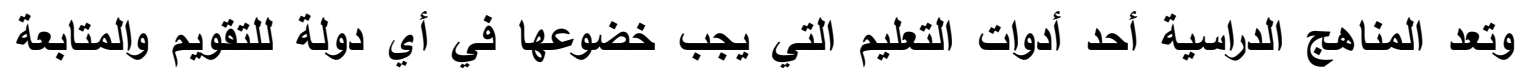

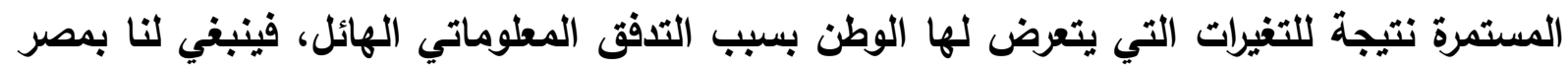

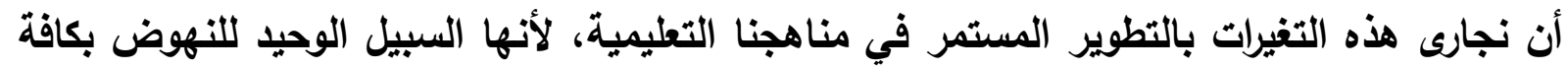
مجالات الحياة. ومصر مثل كل بلدان العالم ستتعرض لهذه التغيرات في شنتى المجالات في المستقبل، ماهن

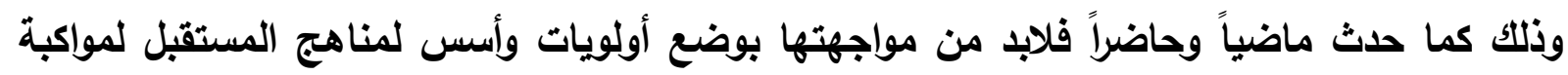

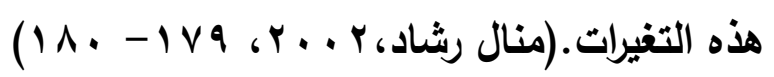

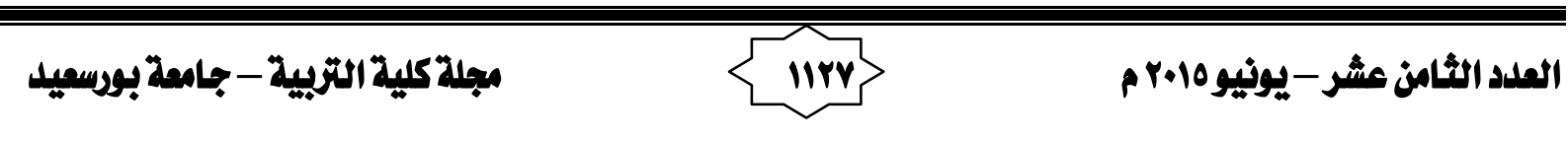


ومن أهم المواد الدراسية التي حظيت بالاهتمام من التقويم والتظوير، مادة الدراسات الاجتماعية، حيث أنها تتناول إنجازات الإنسان وحضارته، وتهتم بأبعاد الزمان وإلمكان وتهتم بالعلاقات الإنسانية المختلفة. والاراسات الاجتماعية كمادة دراسية يجب التمهيا لها بدراسة جادة للواقع الحالي، بالإضافة إلى مالى

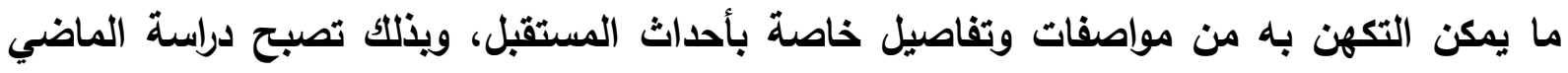

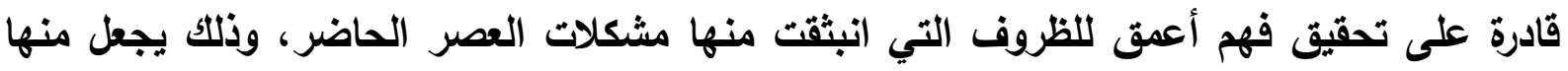

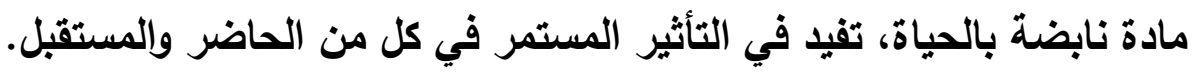

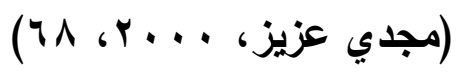

كما تساعد مادة الدراسات الاجتماعية التلاميذ علي فهم الحاضر والتتبؤ بالمستقبل ويناء عقولهم

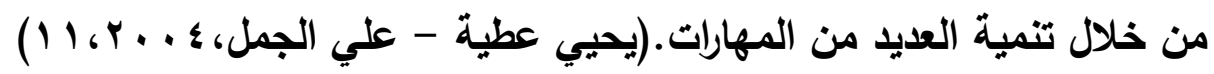

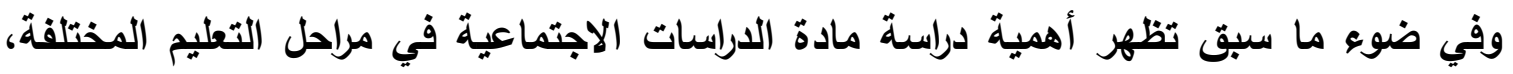

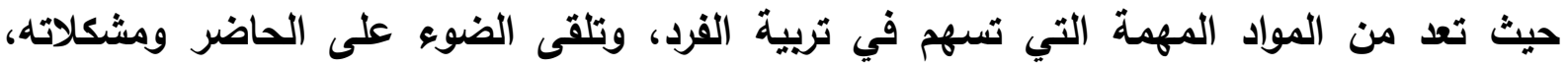
وتكثف عن جذور المشكلات العالمية والمعاصرة، والأسباب التي أدت إليها، وطبيعة هذه الأسباب ونوعها وأثرها. كما يتضح أهمية إعادة النظر في مناهج الاراسات الاجتماعية حتى تصبح ركيزة أساسية من

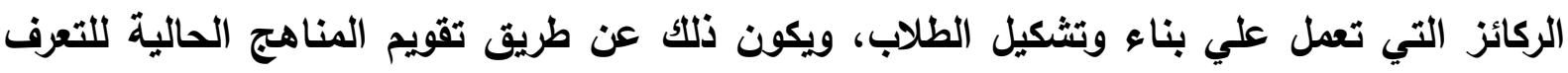
علي مدى مواكبتها للتغيرات العالمية المعاصرة، حيث تعد عملية التقويم خطوة أساسية في سبيل

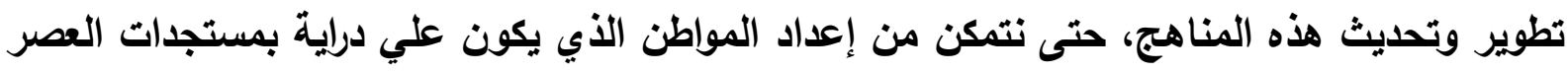

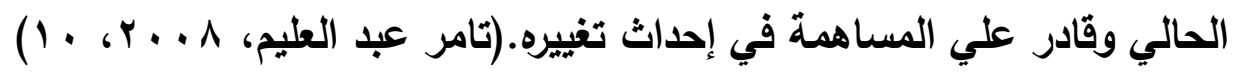
وقد أكلت دراسات عديدة أهمية مهارات القرن الحادي والعشرين في العملية التعليمية وضرورة

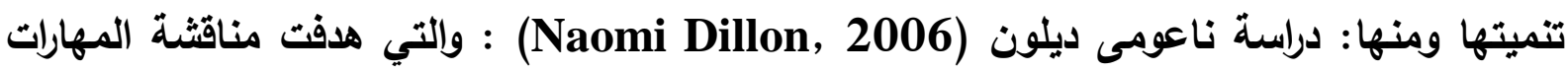

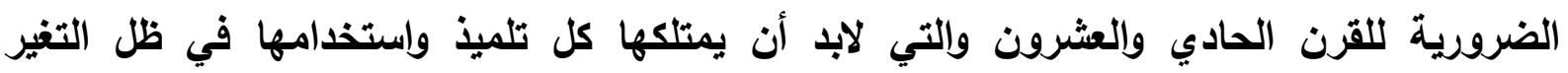

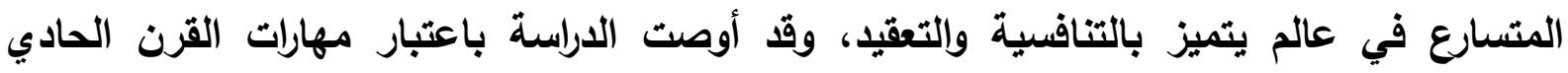
والعشرون هي انعكاساً لمتطلبات سوق العمل. دراسة سوزان كرامير (Susan Cramer, 2007) : والتي هافت تعليث بيئة غرفة الصف والعملية التعليمية من خلال تدريس مهارات القرن الحادي والعشرون، وقد توصلت نتائج الدراسة إلي مجموعة من مهارات القرن الجديد والتي تساعد على تطوير وتحديث العملية التعليمية مثل:

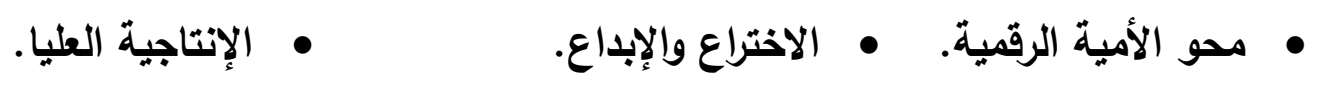

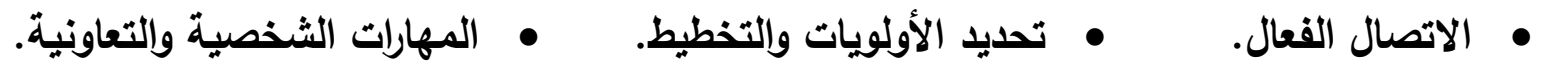

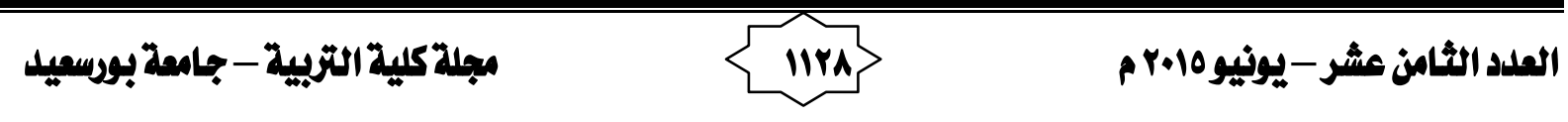


دراسة بوب ريجان (Bob Regan, 2008) : والتي هدفت مناقشة دواعي تدريس مهارات القرن

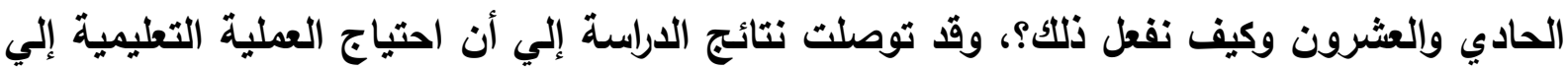
مهارات القرن الحادي والعشرون يسهم في بناء التلميذ وتحضيره لمواجهة العالم الخارجي. دراسة ستيفن (Stephen Sawchuk, 2009) : والتي هدفت مناقثة دور السياسات التعليمية في تطبيق مهارات القرن الحادي والعشرون بالتعليم، وقد أوصت الاراسة بضرورة التأكيد على مهارات القرن الحادي والعشرين أثناء التدريس وحصول جميع التلاميذ على مهارات القرن الحادي والعشرون.

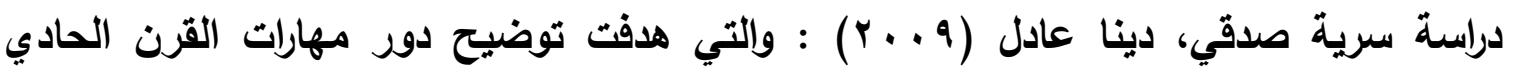

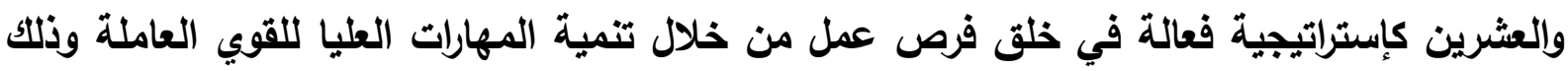

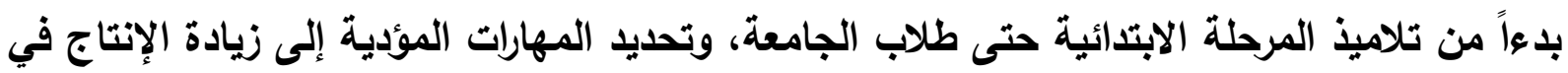

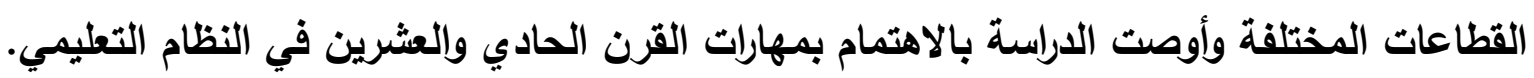

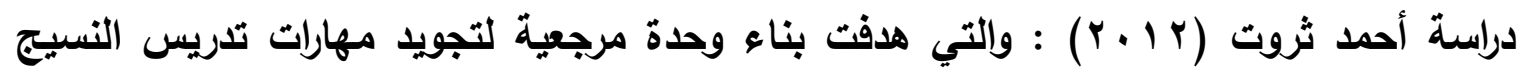
اليدوي للمرحلة الثانوية من خلال تقنيات النسيج القباطي والربط بينها وبين مهارات القرن الواحد

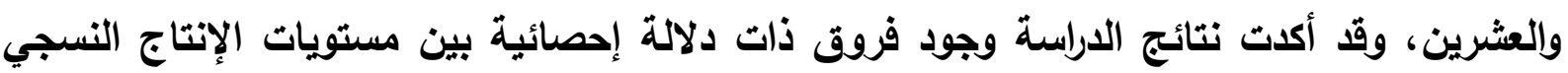

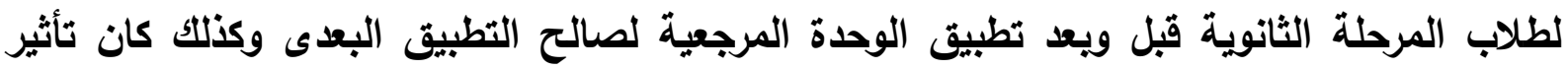
الوحدة المرجعية واضح في تجويد تدريس النسيج اليدوي من خلال تقنيات النسيج القباطي. الإحساس بالمشكلة تنامي الإحساس بالمشكلة لاى الباحثة من خلال:

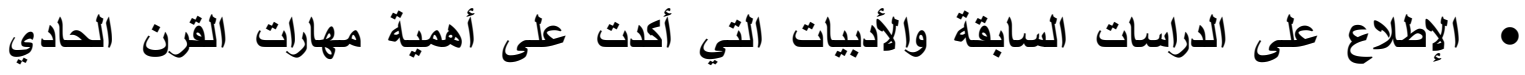

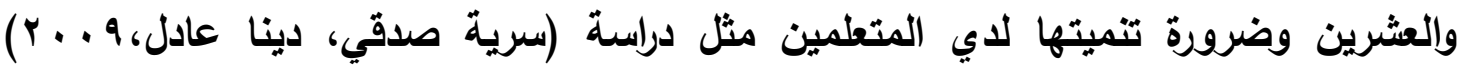

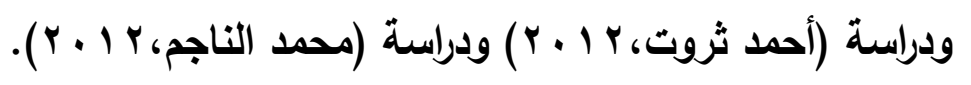

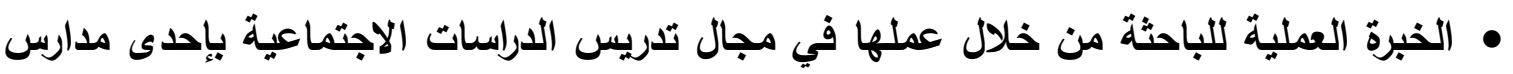

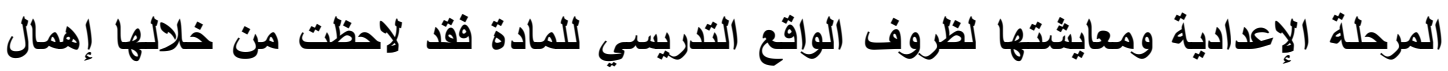

$$
\text { تنمية مهارات القرن الحادي والعشرين لاي التلاميذ. }
$$

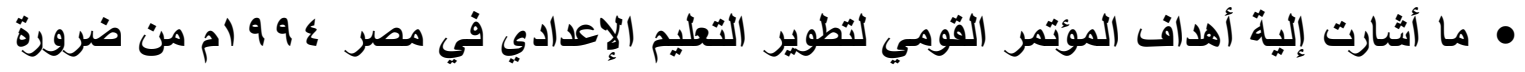

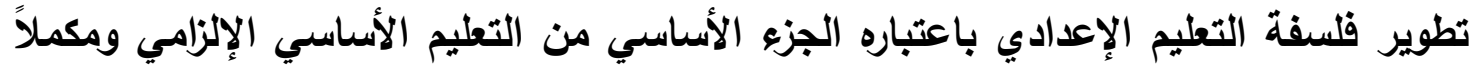
للتعليم الابتدائي ومراعياً الاستعدادات وإلميول المختلفة للتلاميذ.

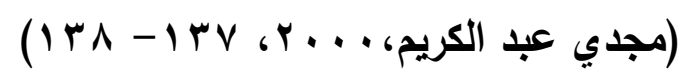

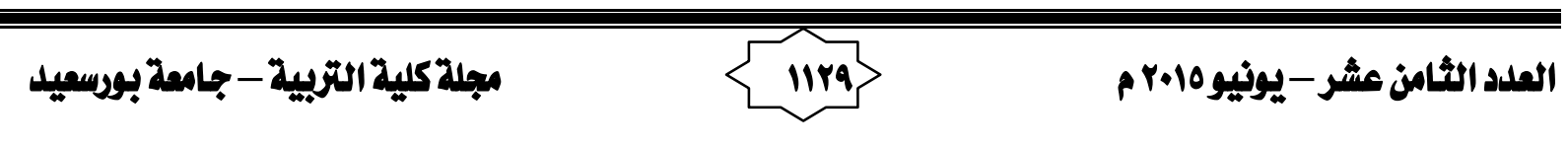


ما أثشارت إليه أهداف المؤتمر العلمي السنوي السابع للإصلاح المؤسسي للتعليم قبل الجامعي

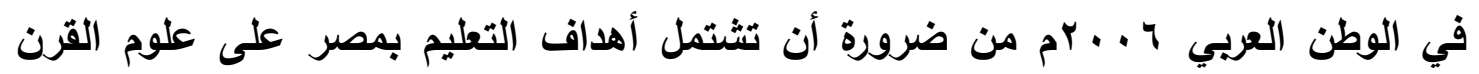

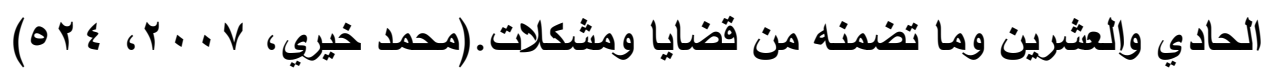

مشكلة البحث

تتحدد مشكلة البحث في ضعف مهارات القرن الحادي والعشرين لاى تلاميذ المرحلة الإعدادية

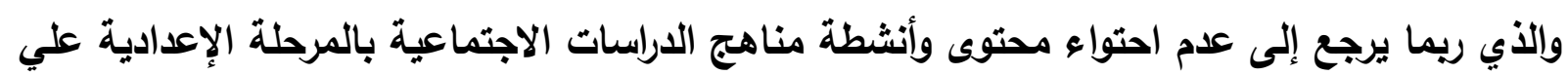
مهارات القرن الحادي والعشرين.

وللتصدي لهذه المشكلة يحاول البحث الحالي الإجابة عن السؤال الرئيس التالي:

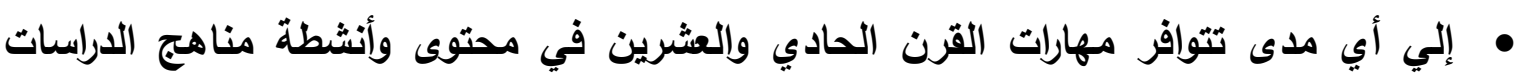

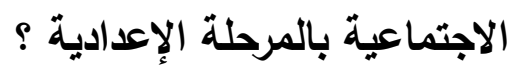

ويتفرع عن السؤال الرئيس الأسئلة الفرعية التالية: ا. ما مهارات القرن الحادي والعشرين اللازم توافرها في محتوى وأنثطة مناهج الدراسات الاجتماعية بالمرحلة الإعدادية؟ r. ما مدي توافر مهارات القرن الحادي والعشرين في محتوى وأنثطة مناهج الاراسات الاجتماعية

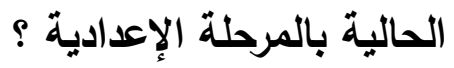

أهداف البحث يهاف البحث الحالي إلى ما يلي: • إعداد قائمة بمهارات القرن الحادي والعشرين اللازم توافرها في محتوى وأنثطة مناهج الاراسات الاجتماعية بالمرحلة الإعدادية.

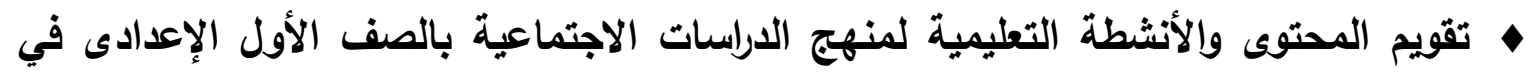
ضوء مهارات القرن الحادي والعشرين، وذلك في ضوء القائمة القدة التي تم التوصل إليها.

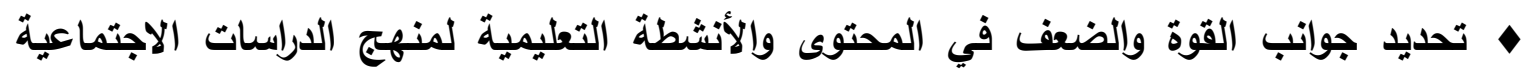
بالصف الأول الإعدادى في ضوي قائمة مهارات القرن الحادي والعشرين. أهمية البحث يفيل هذا البحث فيما يلي: • مساعدة واضعي ومطوري مناهج الداسات الاجتماعية بالمرحلة الإعدادية علي تطوير المناهج في ضوء مهارات القرن الحادي وإلعشرين. اكتساب التلاميذ مهارات القرن الحادي وإلعشرين التي تساعدهم في حياتهر. 


$$
\text { ستقتصر حدود البحث الحالي على: }
$$

• بعض مهارات القرن الحادي والعشرين اللازم توافرها في محتوى وأنشطة مناهج الدراسات الاجتماعية بالمرحلة الإعدادية وهي: مهارات التفكير الناقد، مهارات حل المشكلات، المسئولية

الاجتماعية.

تقويم المحتوى والأنشطة التطليمية لمنهج الدراسات الاجتماعية بالصف الأول الإعدادى كما وردت

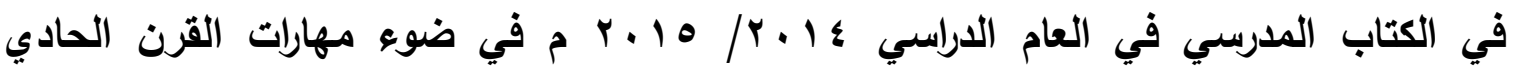

$$
\text { والعشرين. }
$$

مصطلحات البحث

\section{1- تقويم المنهج Evaluation Curriculum}

يعرفه (أحمد اللقاني - على الجمل، 1999 19، ؛ ـ 1) بأنه مجموعة الإجراءات والأساليب التي تتخذ

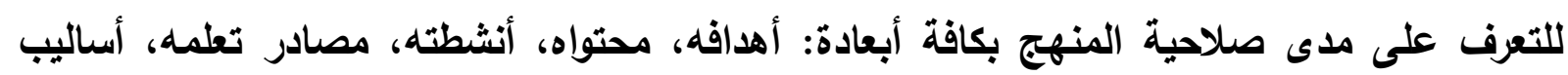
تقويمه، ومدى تحقيقه للأهداف التي وضع من أجلها.

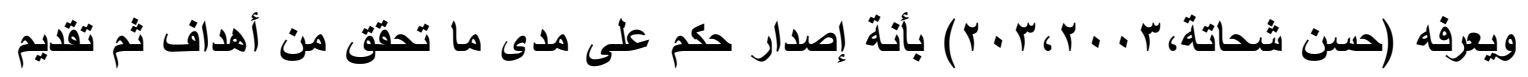
مقترحات للتحسين والتطوير. وتعرف الباحثة تقويم المنهج إجرائياً بأنه مجموعة الإجراءات والأساليب التي تتذذ لمعرفة مدى

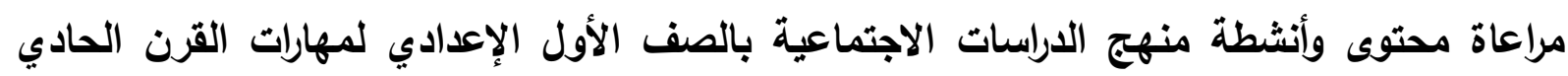
والعشرين من خلال تحليل المنهج وإصدار حكم تجاه.

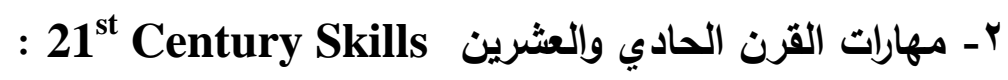
تعرف الشراكة مهارات القرن الحادي والعشرين بأنها المهارات التي يحتاجها المتعلم للنجاح في

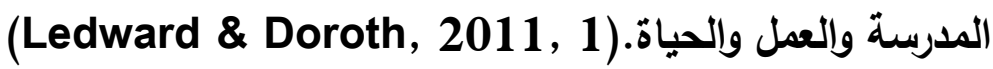

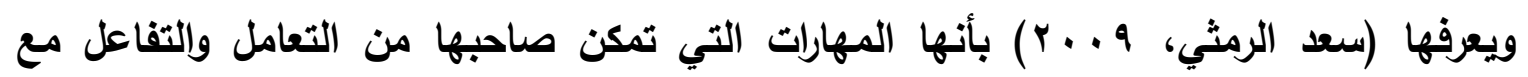
تظورات الحياة في القرن الحادي والعشرين. وتعرف الباحثة مهارات القرن الحادي والعشرين إجرائياً بأنها مجموعة المهارات الأساسية التي

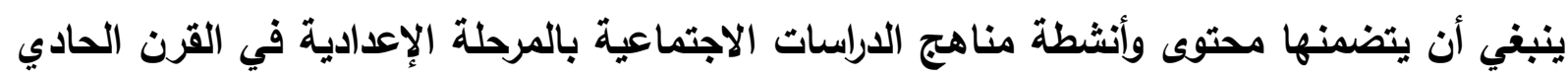

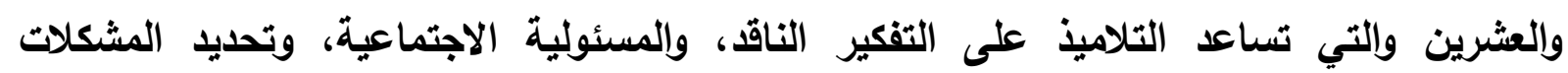
وصياغتها وحلها. 


$$
\text { إجراءات البحث: }
$$

للإجابة على أسئلة البحث اتبعت الباحثة الإجراءات الآتية:

$$
\text { 1. ت الحديد الهلف من التحليل: }
$$

تم إعداد قائمة بمهارات القرن الحادي والعشرين اللازم توافرها في محتوى وأنشطة مناهج الدراسات الاجتماعية بالمرحلة الإعدادية، واشتنملت القائمة في صورتها المبائية على ثلاث مهارات

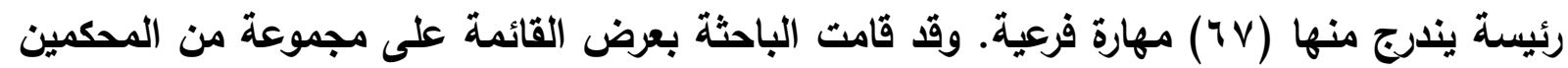

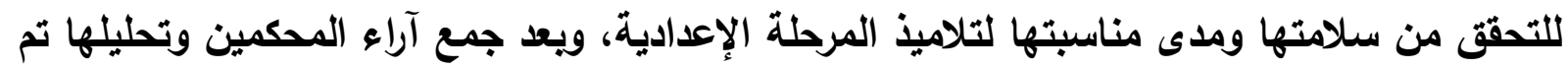

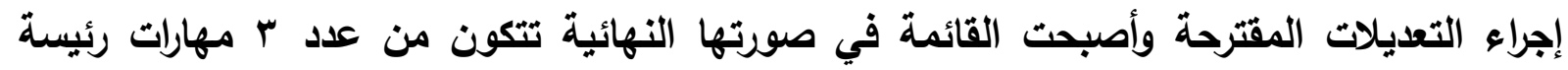

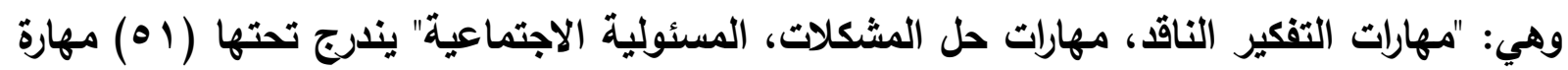
فرعية، ثم طبتت القائمة على محتوى وأنثطة كتابي الاراسات الاجتماعية للصف الأول الإعدادى

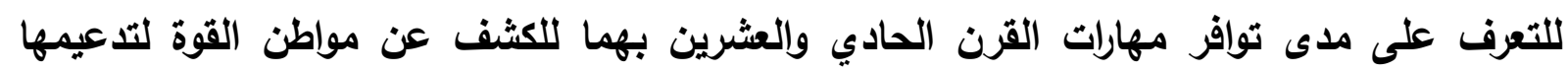
ومواطن الضعف لتعديلها.

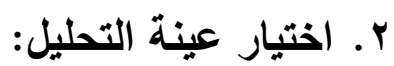

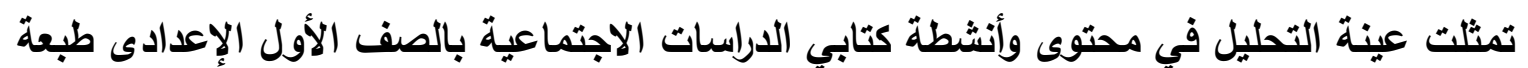

$$
\text { . } 10 / r+1 \leq
$$

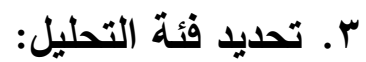

تعل عملية تحديد فئات التحليل من أكثر مراحل تحليل المحتوى أهمية حيث يتوقف عليها نجاح

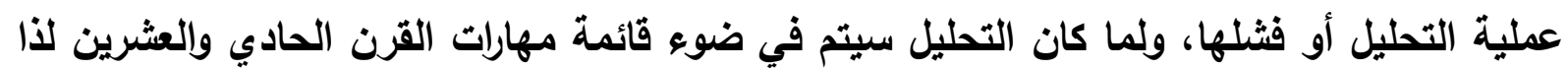

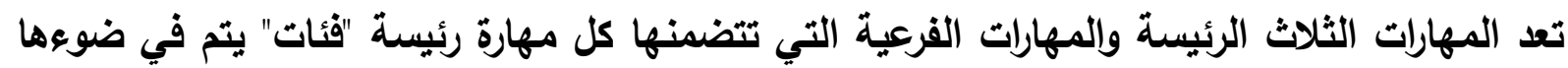
التحليل.

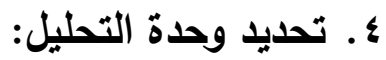
اتخذت الفقرة وحدة للتحليل، حيث أنها الوحدة الطبيعية للمغنى، ولمناسبتها لتحقيق أهداف البحث الحالي، ويقصد بالفقرة جملة أو أكثر تحمل معنى تام.

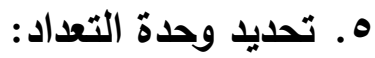

إتخذ التكرار وحدة للتعداد، فعندما تنطبق فقرة ما من فقرات الكتاب على أي مهارة من قائمة المهارات، في أي مهارة من المهارات الثلاث الرئيسة يعطى تكرار ( ل ل) وذلك في الخانة المقابلة لها، وذلك في الجدول الخاص الذي أعد لتسجل فيه نتائج التحليل.

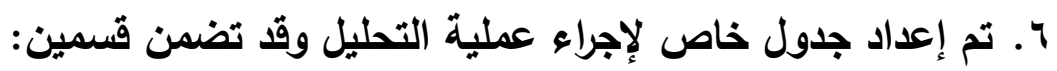
الأول: يتضمن قائمة المهارات الرئيسة الثُلاث والفرعية المنبثقة منها.

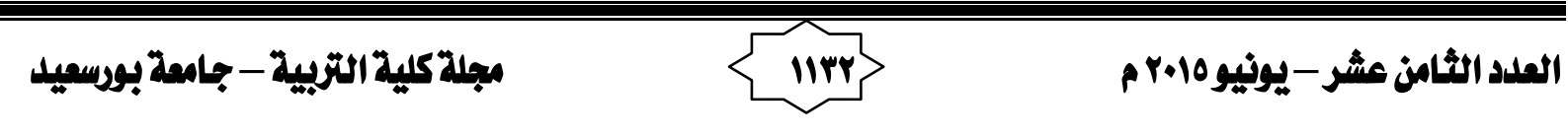


الثانى: يتضمن فقرات المحتوى في كل موضوع من موضوعات المحتوى.

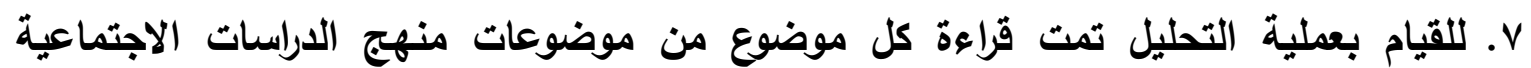

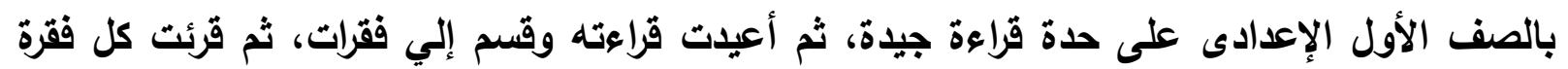
على حدة بتركيز وإنتباه لبيان المهارة التي تنطبق عليها.

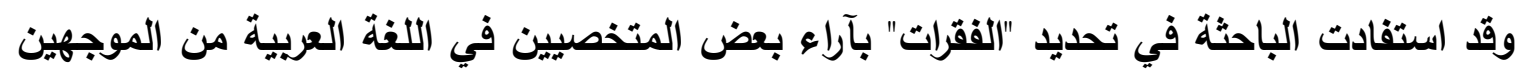
والمدرسين ( ن = 7 )، إلي جانب خبراتها في تحديد بداية ونهاية معنى كل فقرة بحيث لا يتجزأ المعنى.

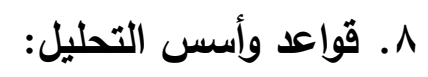

سيتبع أثناء التحليل عدداً من الأسس والقواعد المحدة لتحديد الفقرات الأساسية وتصنيفها كالآتي:

• حينما تظهر في الفقرة الواحدة أكثر من مهارة يثار إليها. • تحديد مهارات القرن الحادي والعشرين الصريحة والضمنية التي وردت بالفقرات. • بشمل التحليل كل العناوين الرئيسة والفرعية بالكتاب المدرسي.

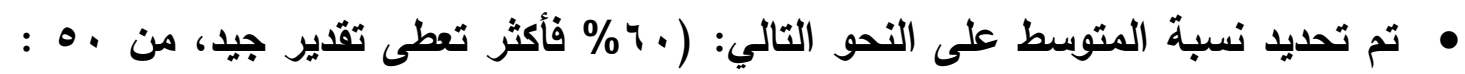

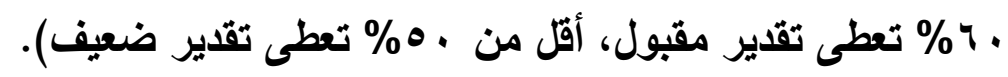

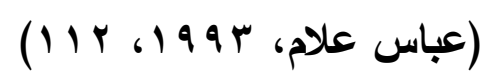

• القيام بإعداد جدول مواصفات وذلك في نهاية التحليل يتضمن النسب المئوية للفقرات التي

$$
\text { تنطبق عليها المهارات. }
$$

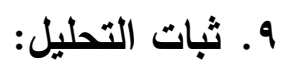

يعرف ثبات التحليل بأنه التوصل إلي نفس النتائج عند تطبيق التحليل في فترتين مختلفتين أو بواسطة باحثين متكافئين.

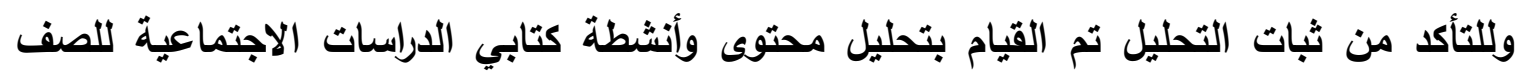

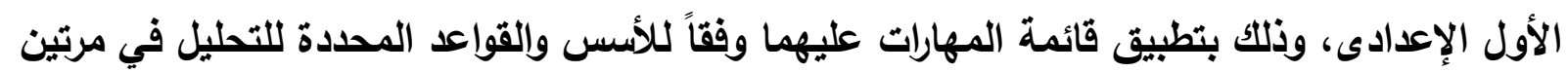
متتاليتين بينهما فاصل زمنى مدته ثلاثون يوماً بواسطة الباحثة.

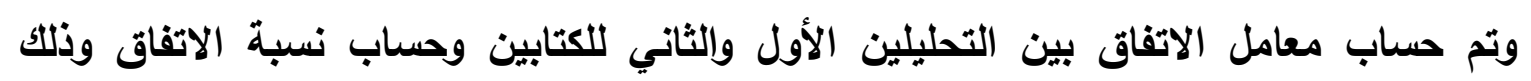

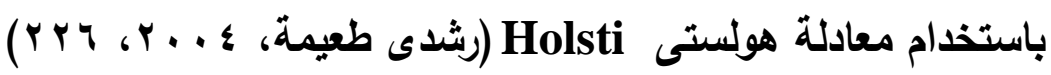

$$
\begin{aligned}
& \mathrm{R}=\frac{2(\mathrm{C} 1,2)}{\mathrm{C} 1+\mathrm{C} 2} \\
& \text { حيث: } \\
& \text { R }
\end{aligned}
$$

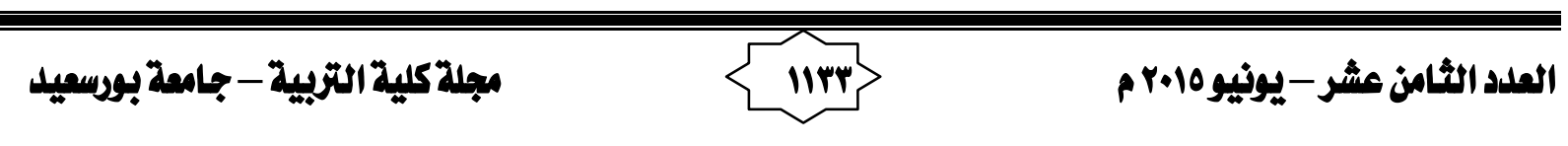


تقويم محتوى وأنشطة مناهج الدراسات الاجتماعية بالمرحلة الإعدادية في ضوء مهارات القرن الحادي والعشرين

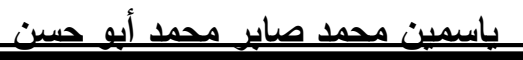

$$
\begin{aligned}
& \text { = C1,2 عدد الفقرات التي يتفق عليها الباحثان أو الباحث نفسه في التحليلين. } \\
& \text { C C1+C2 } \\
& \text { ويضرب الناتج × × . 1 يتم الحصول على معامل الثبات. }
\end{aligned}
$$

وقد بلغت نسبة الاتفاق بين التحليلين الأول والثاني بالنسبة لمحتوى وأنثطة كتاب الاراسات

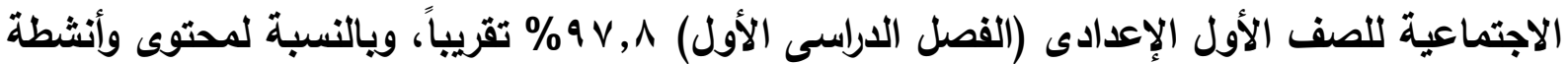

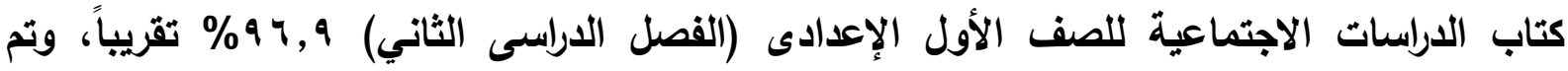

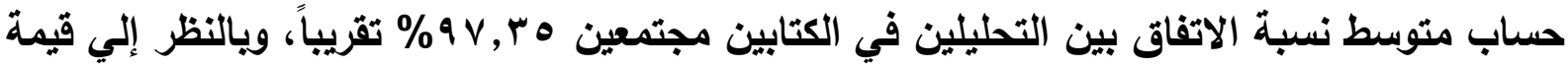
معامل الاتفاق السابقة نجد أنها تلال على نسبة ثبات عالية مما يجعلنا نطمئن على نتائج التحليل.

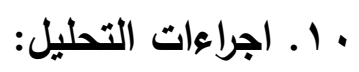

• ثلعليل محتوى وأنثطة كتاب الدراسات الاجتماعية "ظواهر طبيعية وحضارة مصرية" للصف الأول الإعدادي (الفصل الدراسى الأول) ويشتمل على خمس وحدات: تتناول الوحدة الأولى: " رحلة عير الفضاءع " وتتضمن موضوعات:

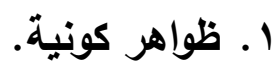

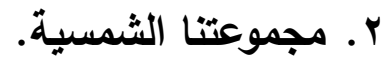
تتناول الوحدة الثانية: " رحلة على كوكب الأرض " وتتضمن الموضوعات التالية:

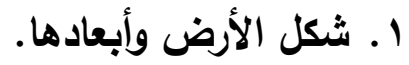
r. الليل والنهار.

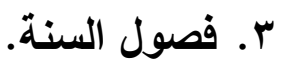
تتناول الوحدة الثالثة: " البابس والماءع " وتتضمن الموضوعات التالية:

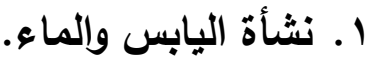

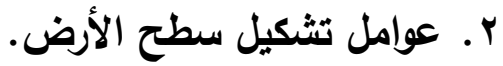

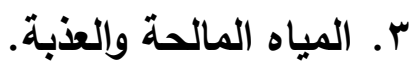
تتناول الوحدة الرابعة: " مصر التاريخ " وتتضضمن الموضوعات التالية:

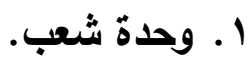
r. عصر بناة الأهرامات ( الاولة القديمة). r. عصر الرخاء الاقتصادى ( الدولة الوسطى). ؛. عصر المجد الحربى ( الدولة الحديثة). 
تقويم محتوى وأنشطة مناهج الدراسات الاجتماعية بالمرحلة الإعدادية في ضوء مهارات القرن الحادي والعشرين

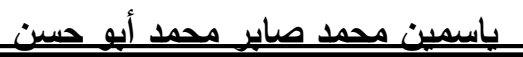

تتناول الوحدة الخامسة: " مصر الحضارة " وتتضمن الموضوعات التالية:

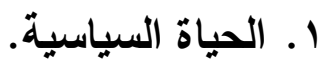

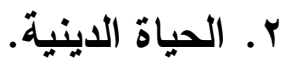

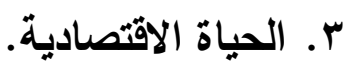

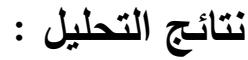

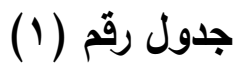

الفقرات التى انطبقت عليها قائمة المهارات في التحليل الأول

\begin{tabular}{|c|c|c|c|c|}
\hline المجموع & المسئولية الاجتماعية & حل المشكلات & التفكير الناق & المهارات \\
\hline ᄉ & & 1. & $\varepsilon r$ & عدد الفقرات \\
\hline . . 1\% تقريباً & 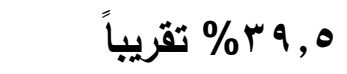 & צ, 11\% تقريباً & 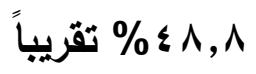 & $\%$ \\
\hline
\end{tabular}

يتضح من الجدول رقم (1) ما يلى:

• أن عدد الفقرات الأساسية الكلى في محتوى وأنثطة كتاب الصف الأول الإعدادى (الفصل الدراسى

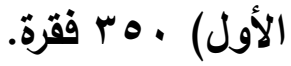

• أن عدد الفقرات التى انطبقت عليها قائمة المهارات هو 1 النه فقرة، ويذلك تكون نسبة الفقرات التي

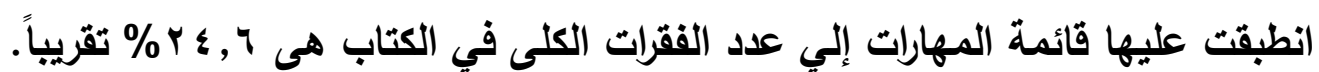
• ولقد بلغ عدد الفقرات التى انطبقت عليها قائمة مهارات القرن الحادى والعشرين في المهارة

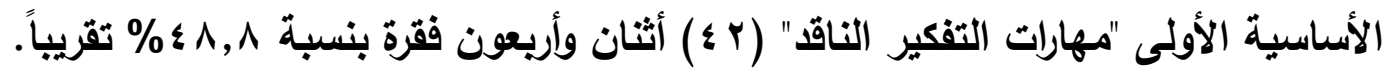

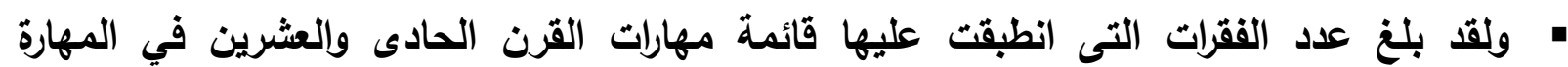

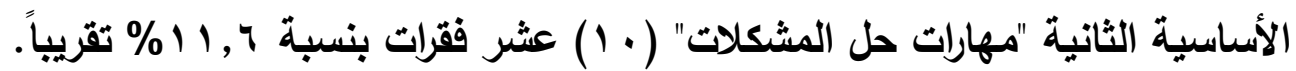
• ولقد بلغ عدد الفقرات التى انطبقت عليها قائمة مهارات القرن الحادى والعشرين في المهارة

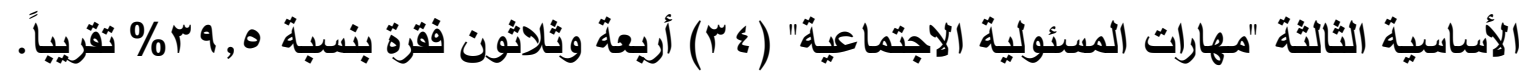

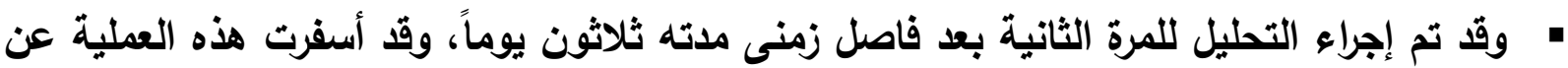

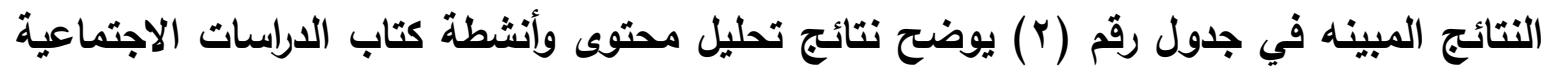
للصف الأول الإعدادى "الفصل الدراسى الأول" (التحليل الثانى). 
تقويم محتوى وأنشطة مناهج الدراسات الاجتماعية بالمرحلة الإعدادية في ضوء مهارات القرن الحادي والعشرين

$$
\text { جدول رقم (r) }
$$

\begin{tabular}{|c|c|c|c|c|}
\hline المجموع & المسئولية الاجتماعية & حل المشكلات & التفكير الناقد & المهارات \\
\hline$\Lambda r$ & ه p & $\Lambda$ & rq & عدد الفقرات \\
\hline . . 1\% تقريباً & \& \& Y V تقريباً & ^, 9 \% تقريباً & 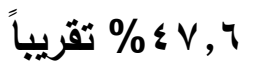 & $\%$ \\
\hline
\end{tabular}

مقارنة نتائج التحليلين الأول والثانى لمحتوى وأنثطة كتاب الاراسات الاجتماعية للصف الأول الإعدادى "الفصل الدراسى الأول":

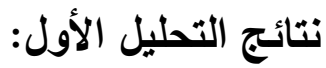

- - عدد الفقرات الكلى لموضوعات الكتاب ( • هـ) فقرة. - عدد الفقرات التي انطبقت عليها قائمة المهارات ( آم) فقرة.

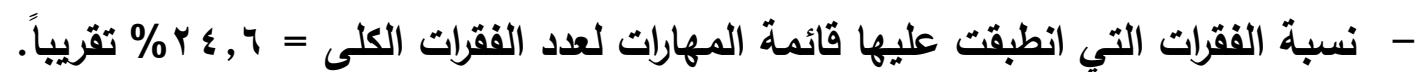
نتائج التحليل الثانى:

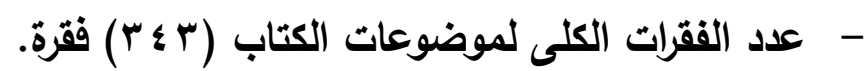

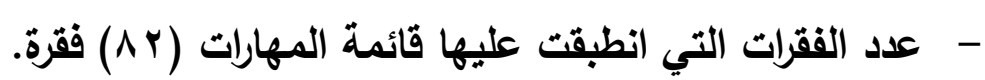

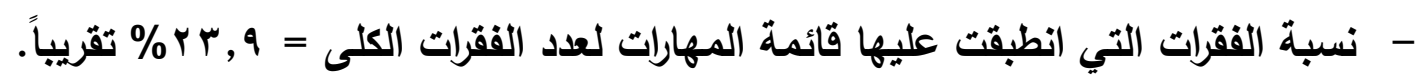

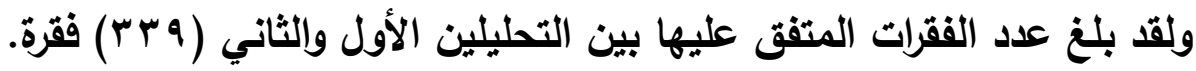

• ثليل محتوى وأنثطة كتاب الدراسات الاجتماعية "ظواهر طبيعية وحضارة مصرية" للصف

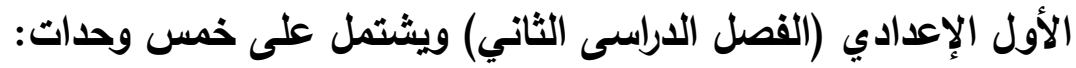
تتناول الوحدة الأولى: " المناخ والنبات الطيعي " وتتضمن الموضوعات التالية:

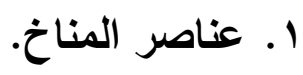

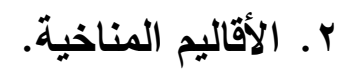
r. النبات الطبيعي والحيوان البري. تتناول الوحدة الثانية: " الأخطار الطبيعية والبيئية " وتتضمن الموضوعات التري، التالية:

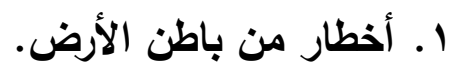

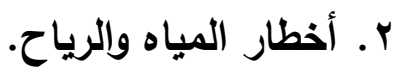

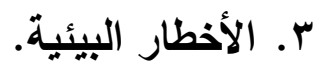


تقويم محتوى وأنشطة مناهج الدراسات الاجتماعية بالمرحلة الإعدادية في ضوء مهارات القرن الحادي والعشرين

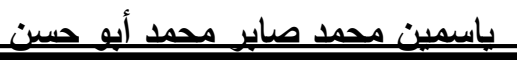

تتناول الوحدة الثالثة: " من روائع حضارتنا ( مظاهر الحضارة المصرية القديمة) " وتتضمن الموضوعات التالية:

1. الحياة الاجتماعية.

$$
\text { r. إبداعات مصرية ( الكتابة- الأدب). }
$$

r. الحياة الثقافية وإلفكرية ( العلم- العمارة- الفن). العابه).

تتناول الوحدة الرابعة: " مصر بين حكر البطالمة والرومان " وتتضمن الموضوعات التهات التالية:

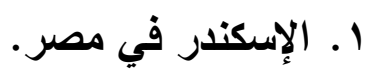

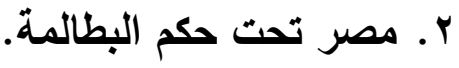

r. (ب مصر تحت حكم الرومان.

ع. مصر والمسيحية.

تتناول الوحدة الخامسة: " المواطنة الصالحة " وتتضمن الموضوعات التالية:

1. كيف تكون موإطناً صالحاً؟

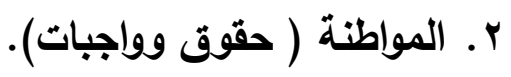

r. r r أنت والقانون.

نتائج التحليل :

\begin{tabular}{|c|c|c|c|c|}
\hline المجموع & المسئولية الاجتماعية & حل المشكلات & التفكير الناقد & المهارات \\
\hline 91 & r r & rq & $\varepsilon$. & عدد الفقرات \\
\hline . . . 1\% تقريباً & 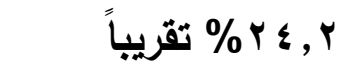 & q, ابr\% تقريباً & ؟ § \% تقريباً & $\%$ \\
\hline
\end{tabular}

جدول رقم (ץ) الفقرات التى انطبقت عليها قائمة المهارات في التحليل الأول

$$
\text { يتضح من الجدول رقم (ץ) ما يلى: }
$$

• أن عدد الفقرات الأساسية الكلى في محتوى وأنثطة كتاب الصف الأول الإعدادى (الفصل

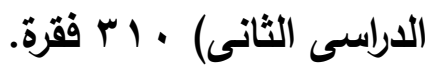

" أن عدد الفقرات التى انطبقت عليها قائمة المهارات هو اهو فقرة، ويذلك تكون نسبة الفقرات

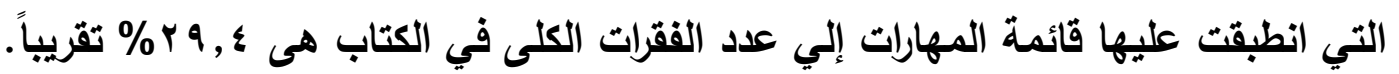
ولقد بلغ عدد الفقرات التى انطبقت عليها قائمة مهارات القرن الحادى والعشرين في المهارة

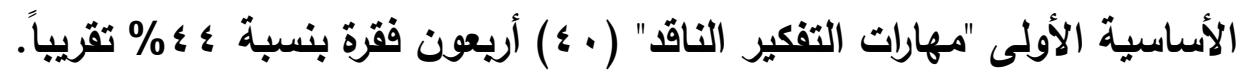

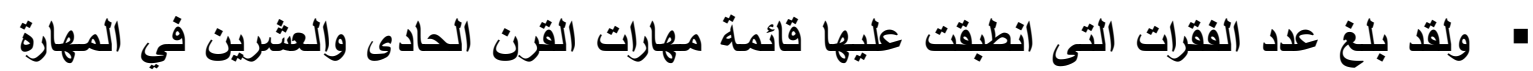

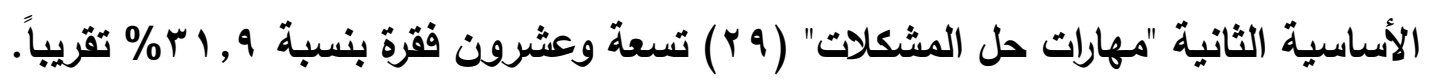

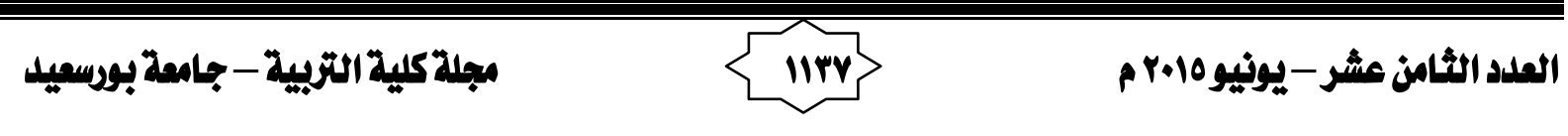


• ولقد بلغ علد الفقرات التى انطقت عليها قائمة مهارات القرن الحادى والعشرين في المهارة

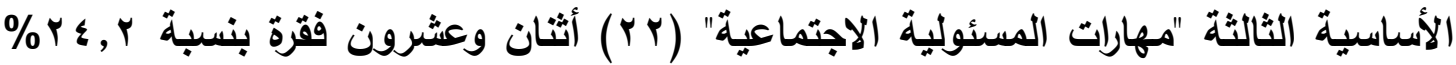
تقريباً.

• وقد تم إجراء التحليل للمرة الثانية بعد فاصل زمنى مدته ثلاثون يوماً، وقد أسفرت هذه العملية عن النتائج المبينه في جدول رقم (؛ ) يوضح نتائج تحليل محتوى وأنشطة كتاب الاراسات الاجتماعية للصف الأول الإعدادى "الفصل الاراسى الثانى" (التحليل الثانى).

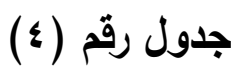

الفقرات التى انطبقت عليها قائمة المهارات في التحليل الثانى

\begin{tabular}{|c|c|c|c|c|}
\hline المجموع & الاجتماعئولية & حل المشكلات & التفكير الناقد & المهارات \\
\hline 10 & 19 & $r$. & T & عدد الفقرات \\
\hline . . 1 \% تقريباً & צ , Y Y \% تقريباً & r, ه \% " تقريباً & 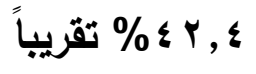 & $\%$ \\
\hline
\end{tabular}

مقارنة نتائج التحليلين الأول والثانى لمحتوى وأنشطة كتاب الدراسات الاجتماعية للصف الأول الإعدادى "الفصل الدراسى الثانى":

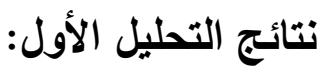

- - عدد الفقرات الكلى لموضوعات الكتاب ( • الع) فقرة.

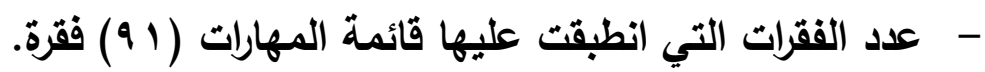

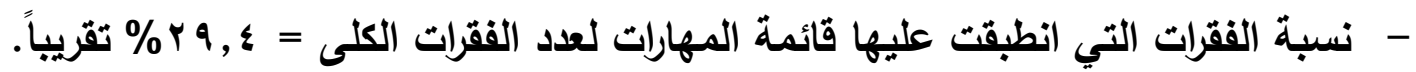

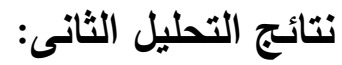

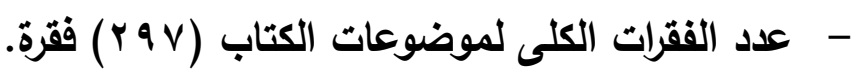

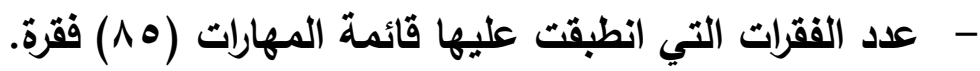

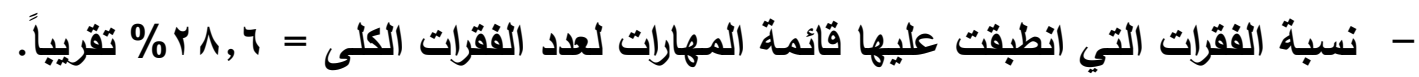

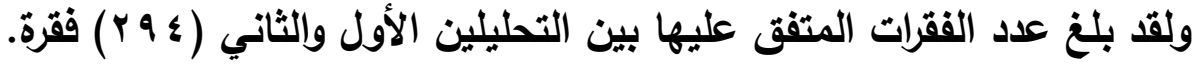

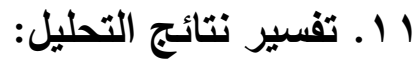
• ملاحظ من خلال تحليل محتوى وأنثطة موضوعات كتاب الدراسات الاجتماعية "ظواهر

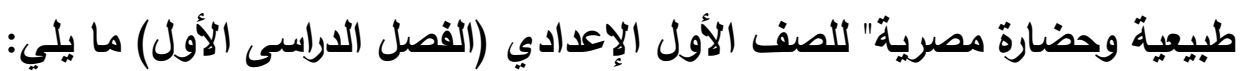

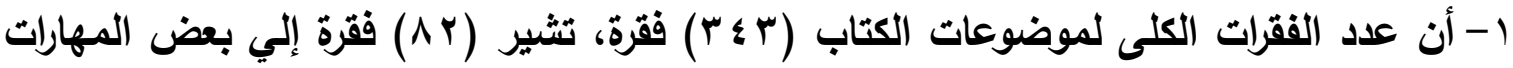

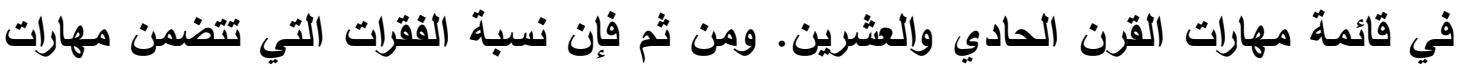




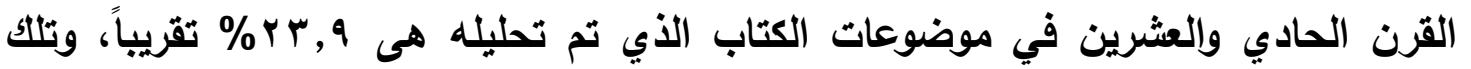

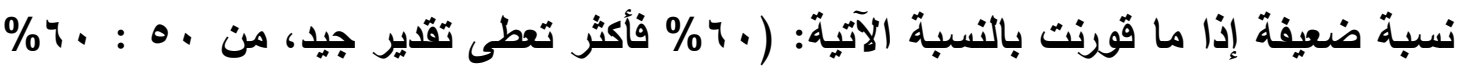

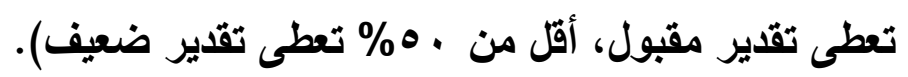

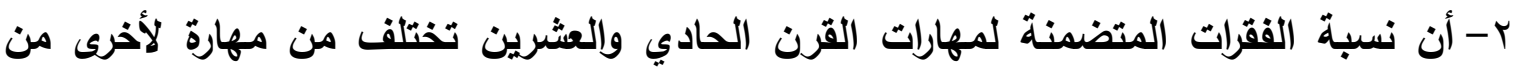
مهارات القائمة.

فبينما نجد أن نسبة الفقرات المتضمنة بمهارات القرن الحادي والعشرين في المهارة الرئيسة

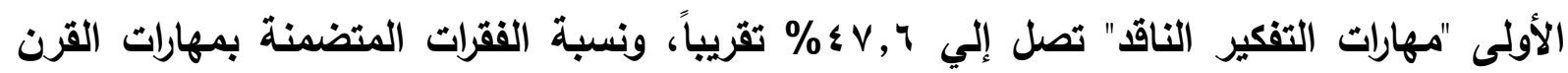

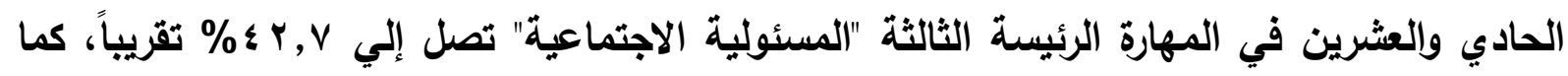

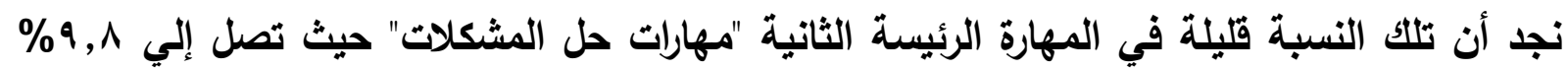
تقريباً. وهذا يرجع بصفة عامة إلي أن محتوى موضوعات كتاب الدراسات الاجتماعية للصف الأول

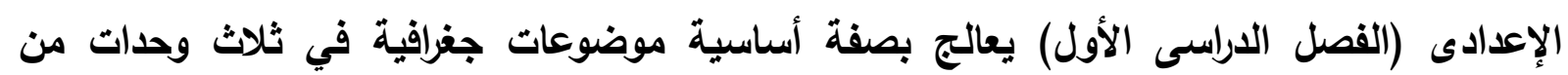

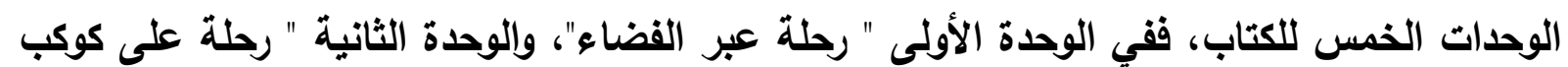
الأرض"، والوحدة الثالثة " اليابس وإلماء". كما أن الوحدتين المتبقيتين من المحتوى موضوعات تاريخية وهى الوحدة الرابعة "مصر التاريخ (تاريخ مصر عبر العصور القيمة)"، والوحدة الخامسة "مصر الحضارة (مظاهر الحضارة المصرية المونية (القديمة)".

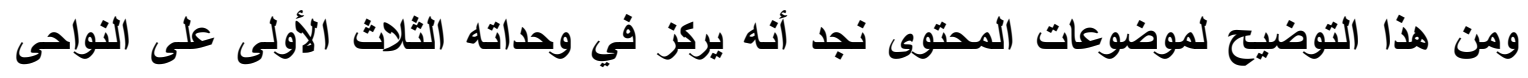

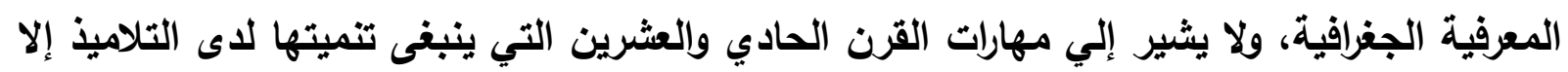
في مواضع قليلة، كما سيتضع فيما بعد. أما بالنسبة للوحدة الرابعة والوحدة الخامسة نجد أنها دروساً تاريخية يميل المحتوى فيها إلي

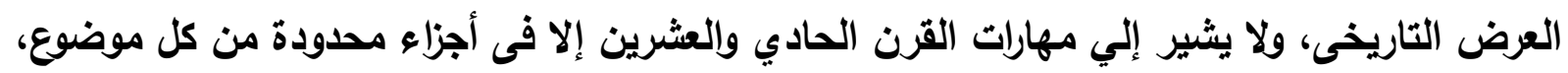
وإلمهارة غالباً ما تكون غير مباشرة. ففي المهارة الأولى "مهارات التفكير الناقد":

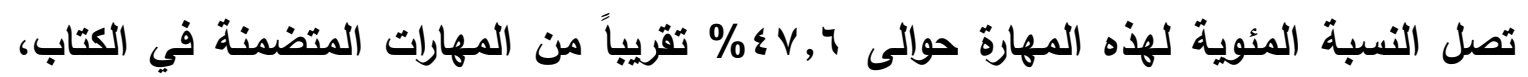

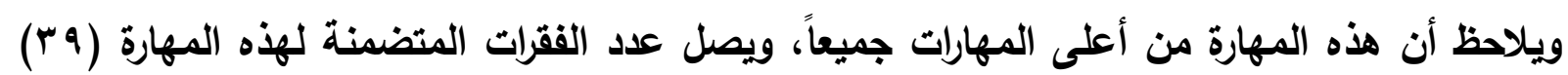
فقرة جاءت كالتالي: - المهارة رقم (ץ) "جمع المطلومات ذات الصلة بالموضوع" تكررت أريع مرات، وتتضح هذه

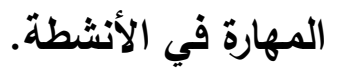

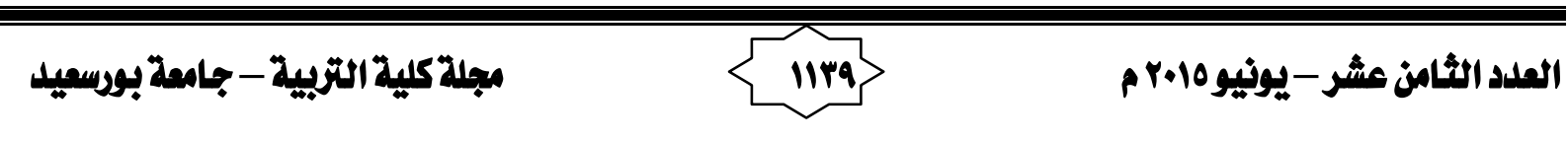




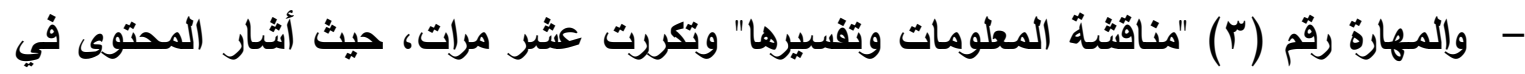

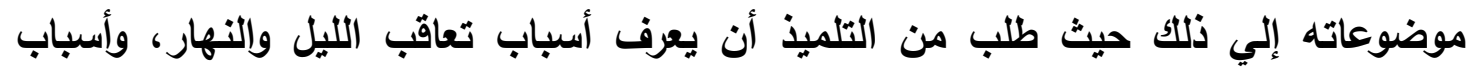
تعاقب فصول السنة الأربعة، وكذلك أهمية الماء. - والمهارة رقم (†) "تحديد النقاط الرئيسة" وتكررت أربع مرات، وقد ظهرت هذهاء هذه المهارة بصورة

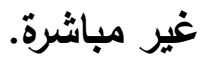

- - والمهارة رقم (^) "استنتاج الأفكار الفرعية من الأفكار الرئيسة" وتكررت مرة واحدة.

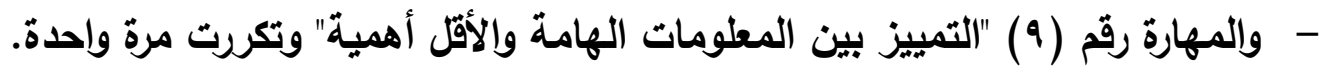
- والمهارة رقم (• 1) "مساعدة التلميذ على الخروج باستتتاجات" وتكررت عشر مرات، حيث أثشار المحتوى في بعض الفقرات إلي ذلك حيث طلب من التلميذ أن يستتنج العديد من الحقائق،

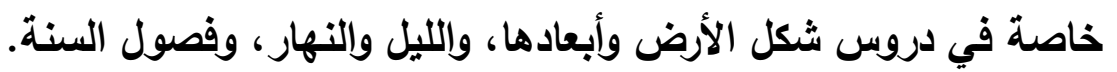
- والمهارة رقم (0 1 ) "مساعدة التلميذ على استخلاص النتائج" وتكررت أريع مرات.

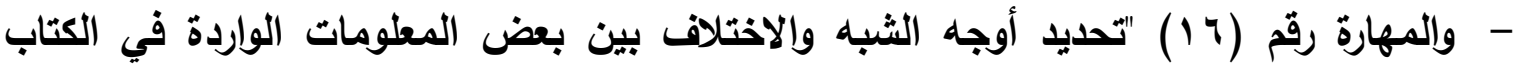
المدرسى" وتكررت خمس مرات، حيث أثشار المحتوى في بعض الفقرات إلي ذلك حيث طلب من التلميذ أن يقارن بين كواكب المجموعة الشمسية بعضها البعض، وأن يقارن بين فصول السنة الأريعة، وكذلك المقارنة بين مملكة الشمال ومملكة الجنوب. - - ولم تظهر بقية المهارات في أية فقرات أخرى. وفي المهارة الثانية "مهارات حل المشكلات": تصل النسبة المئوية لهذه المهارة حوالى ^, 9\% تقريباً من المهارات المتضمنة في الكتاب، ويصل عدد الفقرات المتضمنة لهذه المهارة (^) فقرات توزيعها كالتالي:

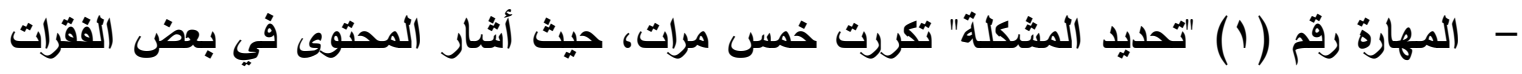

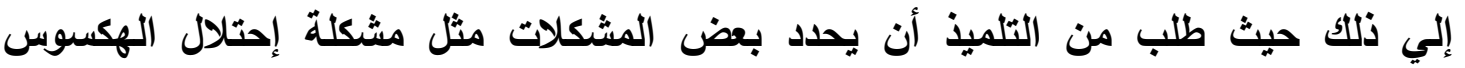
لمصر. - والمهارة رقم (^) "تحديد الفكرة الرئيسة المتعلقة بالمشكلة" وتكررت ثلاث مرات، وقث ظهرث هذه المهارة بصورة غير مباشرة. - وهذه نسبة ضئيلة جاً في هذه المهارة على الرغم من أهميتها القصوى، حيث لم تعرض موضوعات المحتوى على هيئة قضايا ومشكلات يمكن توظيفها لتنمية مهارات حل المشكلات

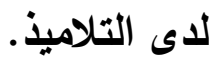


وفي المهارة الثالثة "المسئولية الاجتماعية": تصل النسبة المئوية لهذه المهارة حوالى Y,V؛\% تقريباً من المهارات المتضمنة في الكتاب،

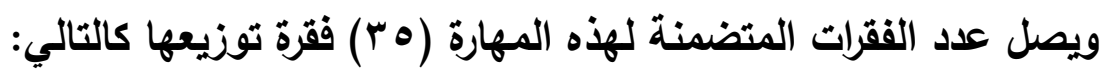
- المهارة رقم (ه) "مساعدة التلميذ للجماعة في تلبية احتياجاتها" تكررت مرتين.

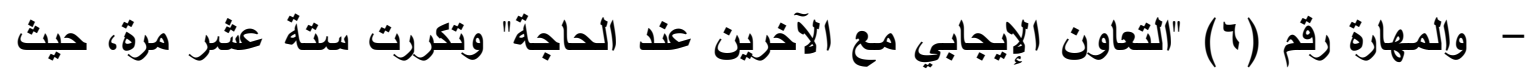

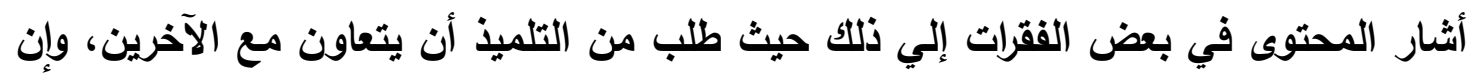
جاءت هذه المهارة في أغلب الأحيان بصورة غير الفير مباشئرة.

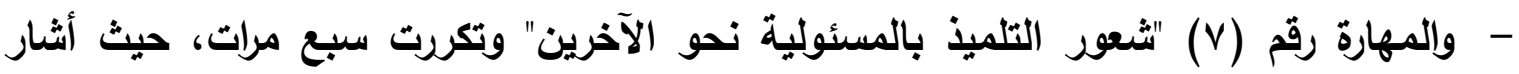
المحتوى إلي الدور الكبير الذي قدمته الثخصيات التاريخية التي وردت بالكتاب مثل (مينا(أحمس). - - والمهارة رقم (^) "الإخلاص في العمل الجماعى والتفانى فيه" وتكررت أريع مرات.

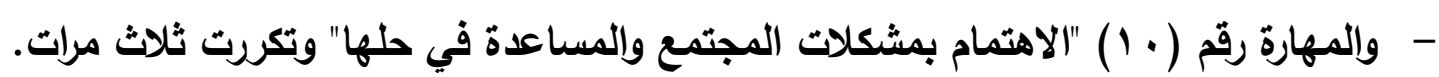

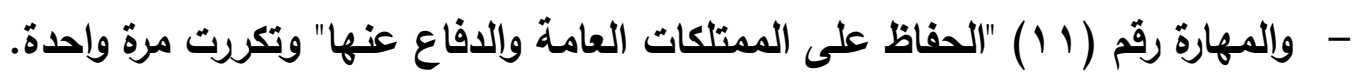

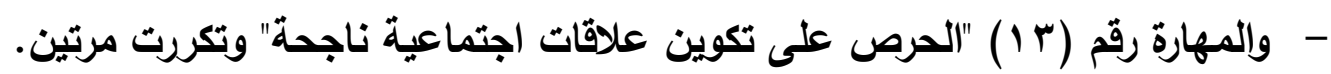
- ميالنسبة لبقية المهارات لم يثر إليها المحتوى إطلاقةاً. •. يلاحظ من خلال تحليل محتوى وأنشطة موضوعات الاراسات الاجتماعية "ظواهر طبيعية

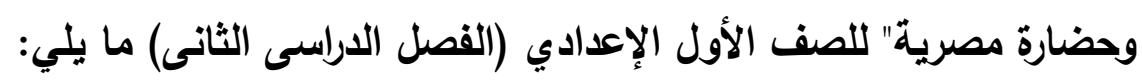

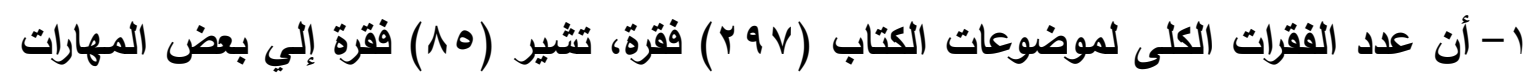

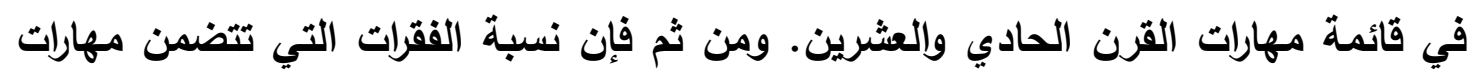

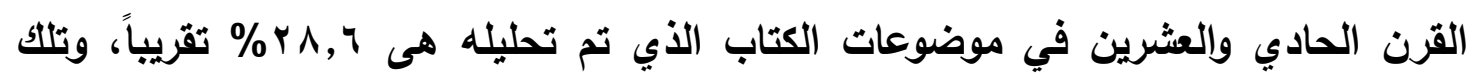

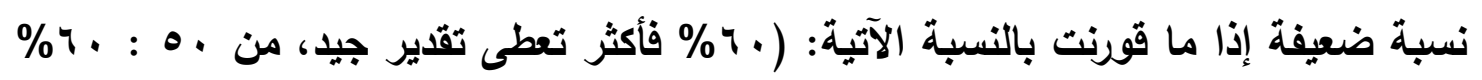
تعطى تقدير مقبول، أقل من •0\% تعطى تقدير ضعيف).

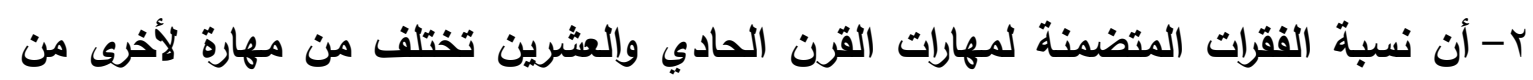
مهارات القائمة. فبينما نجد أن نسبة الفقرات المتضمنة بمهارات القرن الحادي والعشرين في المهارة الرئيسة

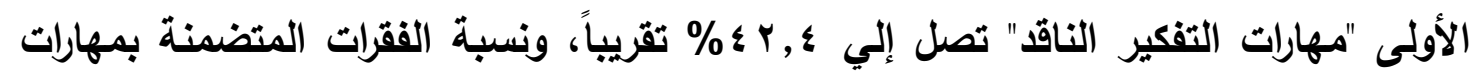

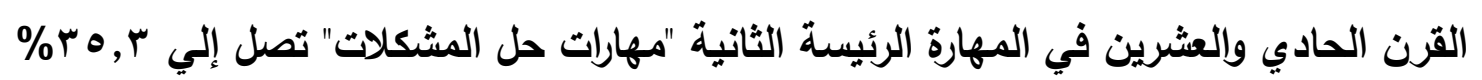

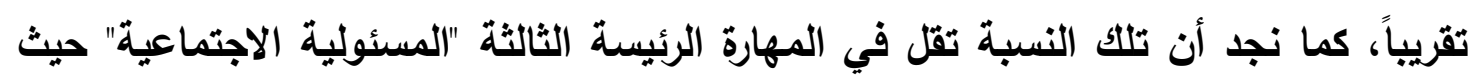

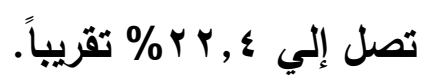


وهذا يرجع بصفة عامة إلي أن محتوى موضوعات كتاب الاراسات الاجتماعية "ظواهر طبيعية

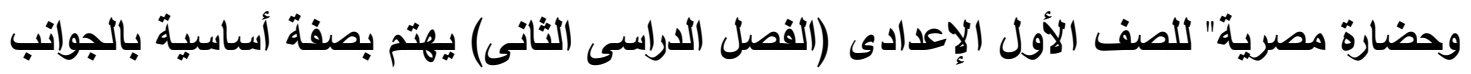

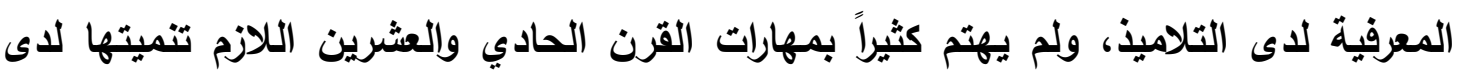
التلاميذ إلا في مواضع قليلة. ففي المهارة الأولى "مهارات التفكير الناقد":

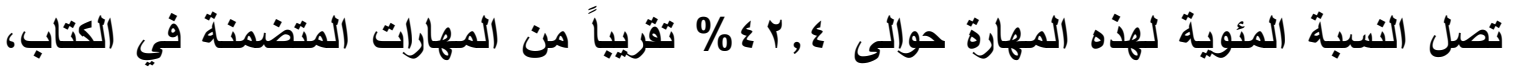

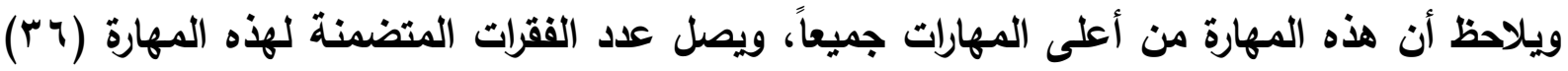
فقرة جاءت كالتالي:

- المهارة رقم (Y) "جمع المعلومات ذات الصلة بالموضوع" تكررت مرة واحدة.

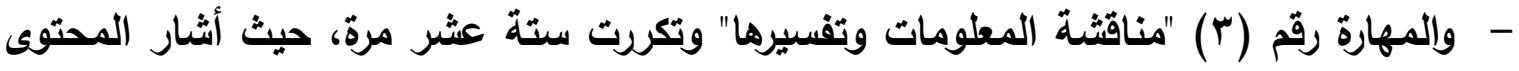

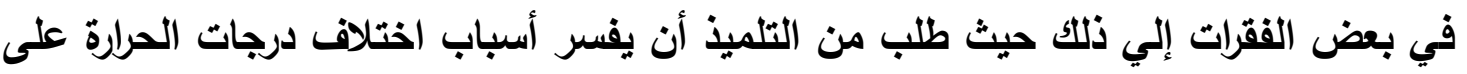

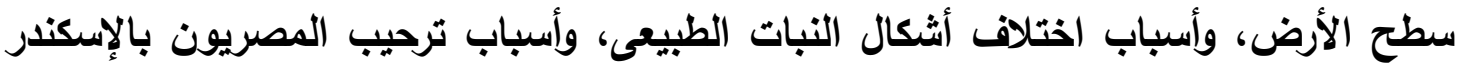
الأكبر، وأسباب إقبال المصريون على إعتناق المسيحية، وخاصة في دروس الأقاليم المناخية، النبات الطبيعى والحيوان البرى، الإسكندر في مصر، والفئ ومصر والمسيحية.

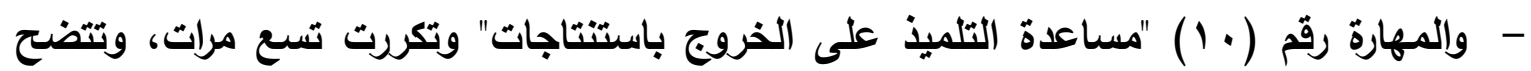
هذه المهارة في الأنشطة. - مالمهارة رقم (ب ا ) "تحديد العلاقة بين السبب والنتيجة" وتكررت مرتين.

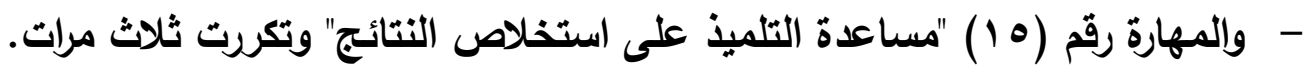

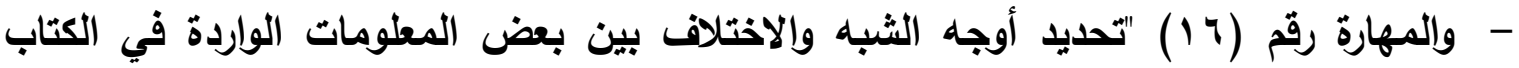
المدرسى" وتكررت ثلاث مرات.

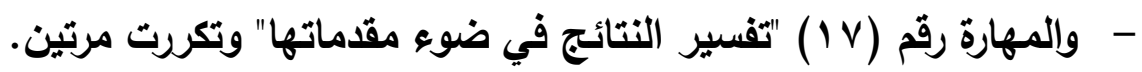
- ميالنسبة لبقية المهارات لم يشر إليها المحتوى إطلاقاً. وفي المهارة الثانية "مهارات حل المشكلات":

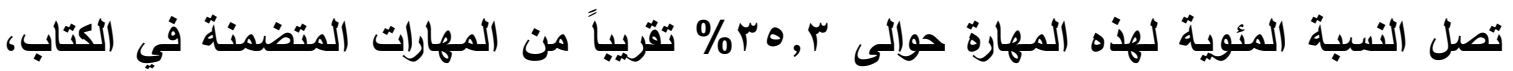

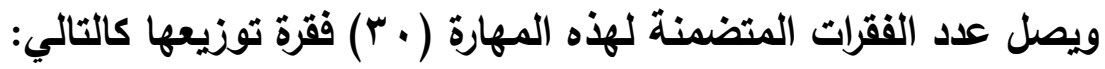

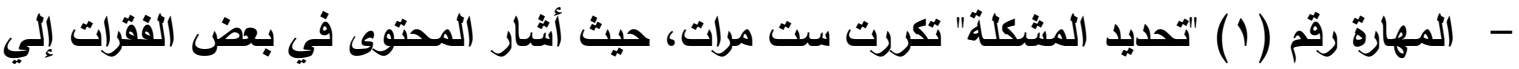
ذلك حيث طلب من التلميذ أن يحدد بعض المشكلات مثل مشكلة (الفيضانات- السيول-

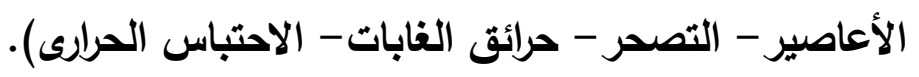


- والمهارة رقم (ץ) "تحديد الأسباب المختلفة للمشكلة" وتكررت ست مرات، حيث أثشار المحتوى

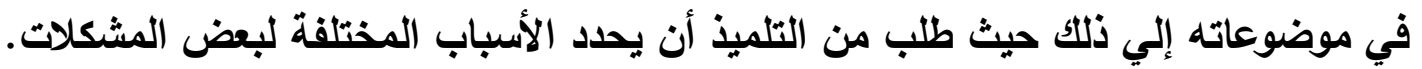

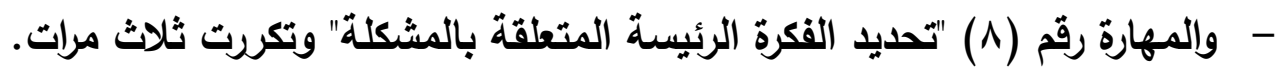

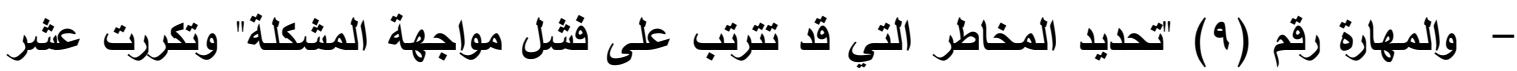

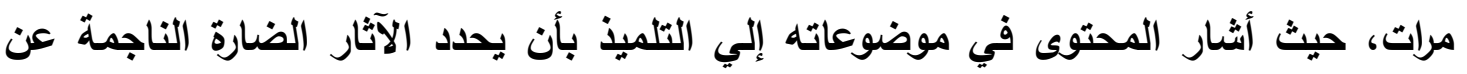
بعض المشكلات. - والمهارة رقم ( 1) "(قتراح عدد من البائل لحل المشكنة" وتكرت خمس مرات، وتتضح هذه المهارة في الأنثطة. - ولم تظهر بقية المهارات في أية فقرات أخرى. وفي المهارة الثالثة "المسئولية الاجتماعية":

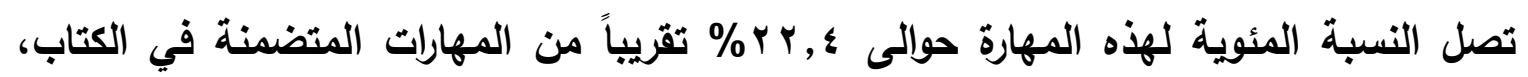

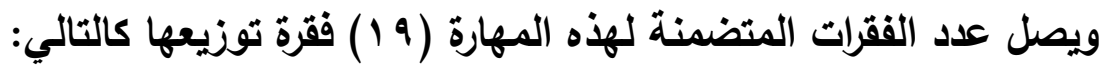
- المهارة رقم (ץ) "فهم التلميذ للجماعة التي ينتمى إليها" تكررت مرتين.

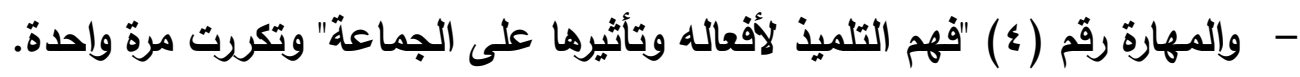
- مالمهارة رقم (ه) "مساعدة التلميذ للجماعة في تلبية احتياجاتها" وتكررت مرة واحدة.

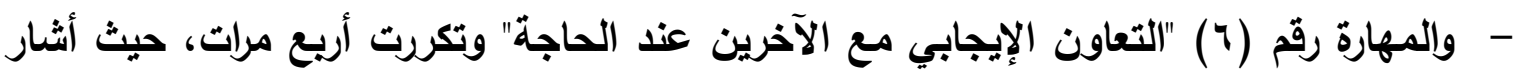
المحتوى في بعض الفقرات إلب ذلك حيث طلب من التلميذ أن يتعاون مع الآخرين. - والمهارة رقم (V) "ثعور التلميذ بالمسئولية نحو الآخرين" وتكررت مرتين.

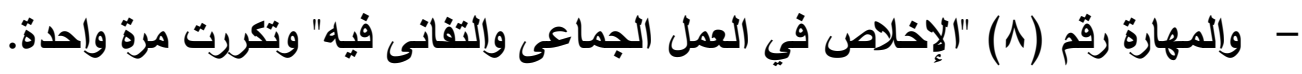

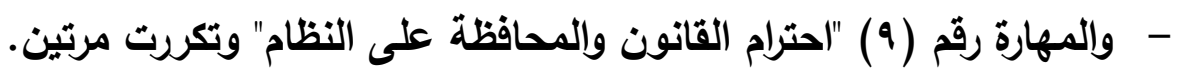

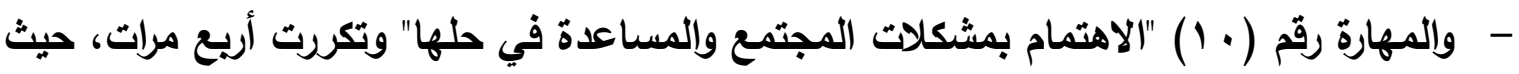

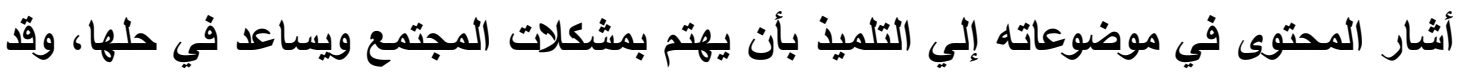

$$
\text { ظهرت هذه المهارة بصورة غير مباشرة. }
$$

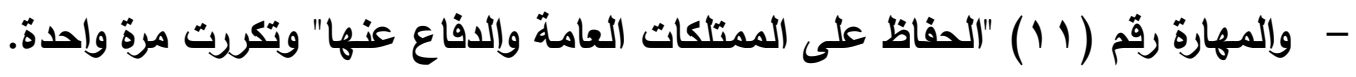
- - والمهارة رقم (ب 1) "الحرص على تكوين علاقات اجتماعية ناجحة" وتكررث مرة واحدة. - ميالنسبة لبقية المهارات لم يشر إليها المحتوى إطلاقاً.

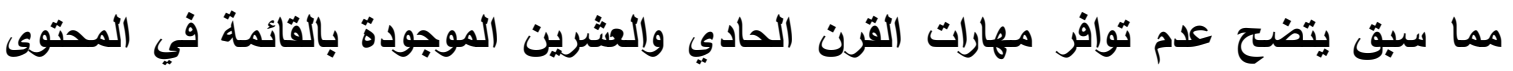
والأنثطة التعليمية لمنهج الدراسات الاجتماعية بالصف الأول الإعدادى إلا بلرجة ضئيلة على الرغم

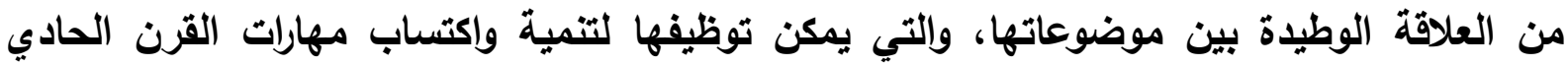


تقويم محتوى وأنشطة مناهج الدراسات الاجتماعية بالمرحلة الإعدادية في ضوء مهارات القرن الحادي والعشرين

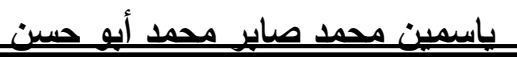

والعشرين، مما يؤكد على أن عرض المادة العلمية كان بطريقة غير شيقة مما يجعل التلميذ غير قادر على اكتساب مهارات التفكير الناقد ومهارات حل المشكلات والمسئولية الاجتماعية.

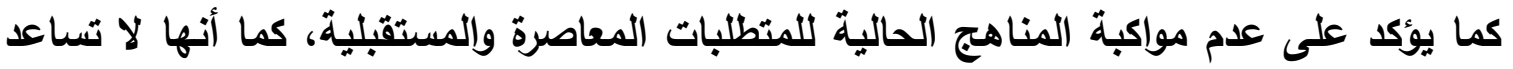
على استفادة التلميذ وتوظيف ما تعلمه في ممارسة حياته ومواجهة التحديات المستقبلية. توصيات البحث

• خ مجي مجال محتوى منهج الدراسات الاجتماعية بالصف الأول الإعدادي: لما كان هذا البحث قد كثف عن أن محتوى منهج الدراسات الاجتماعية يتضمن نسبة ضعيفة من

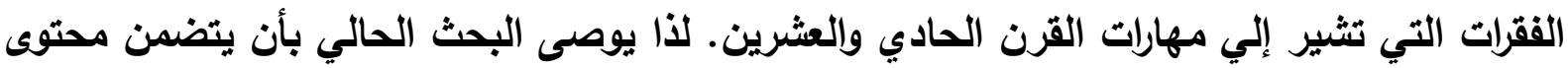

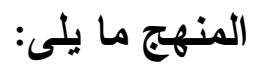
1- أن يشتمل المنهج على تعريف المسئولية الاجتماعية، وشرحها شرحاً مفصلاً يوضح من خلاله ما يجنيه الوطن والفرد من وراء تطبيقها والالتزام بها. r- أن تثتنمل التقاويم التريوية على المواقف التي تظهر فيها روح التعاون مع الآخرين أثناء حل

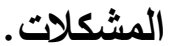

r- إعداد المواطن الإيجابي المشارك بجدية في حل مشكلات مجتمعه. ع - حث التلاميذ على ضرورة الإخلاص في العمل الجماعى وإلتفاني فيه. ه- اكتساب التلاميذ مهارات التفكير الناقد وحل المشكلات. 7- حث التلاميذ على الاشترإك في الجمعيات الخيرية.

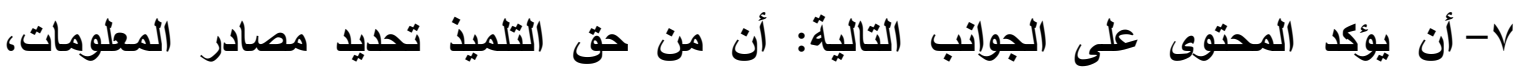
وتقويمها، والبحث عن بائل، والتمييز بين الحقائق والآراء.

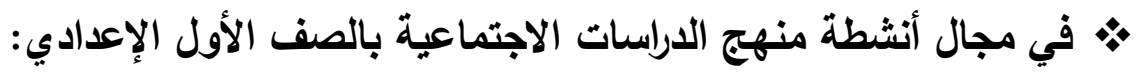
لما كاتت الأنثطة من الوسائل المهمة لاكتساب التلاميذ لمهارات القرن الحادي والعشرين الإين وتتميتها لديهم لذا نوصى بما يلى: 1- عقد الندوات المشتركة بين التلاميذ والمعلمين عن موضوع مهارات القرن الحادي والعشرين، واستدعاء الخبراء في هذا المجال لإلقاء بعض المحاضرات على التلاميذ والإجابة عن أسئلتهم في هذا الصدد.

r- بيام التلاميذ بزيارة الجمعيات الخيرية والاثتراك بها. r- التركيز على الأنثطة التي تثير التفكير لاى التلاميذ. ـ - الاهتمام بممارسة الأنثطة التريوية والثقافية بين التلاميذ من مسرحيات علمية ويحوث وتثقارير

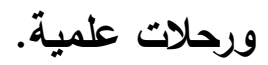


تقويم محتوى وأنشطة مناهج الدراسات الاجتماعية بالمرحلة الإعدادية في ضوء مهارات القرن الحادي والعشرين باسمين محمد صاير محمد أبو حسن وادين

$$
\text { مقترحات ببحوث أخرى }
$$

في ضوء ما توصل إليه البحث الحالي من نتائج وتوصيات يقترح القيام بالدراسات الآتية:

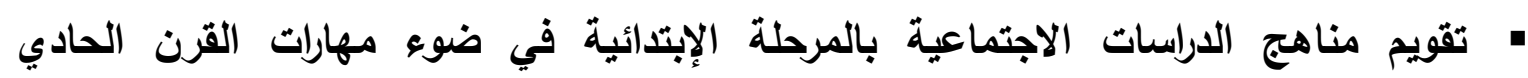
والعثرين.

تطوير مناهج الدراسات الاجتماعية بالمرحلة الإبتدائية في ضوء مهارات القرن الحادي والعشرين.

تطوير مناهج الدراسات الاجتماعية بالمرحلة الإعدادية في ضوء مهارات القرن الحادي والعشرين. تصور مقترح لمناهج الدراسات الاجتماعية بالمرحلة الإعدادية في ضوء مهارات القرن الحادي والعشرين. • إعداد برنامج لتدريب معلم الاراسات الاجتماعية أثناء الخدمة لتنمية مهارات التريس للقرن الحادي والعشرين. 


\section{المراجع}

$$
\text { أولاًا : المراجع العربية }
$$

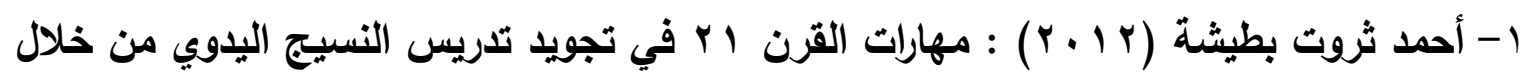

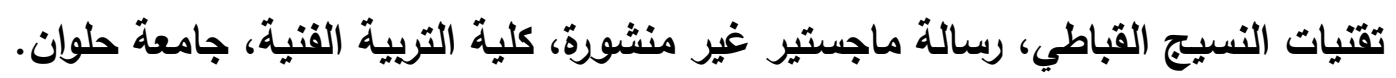

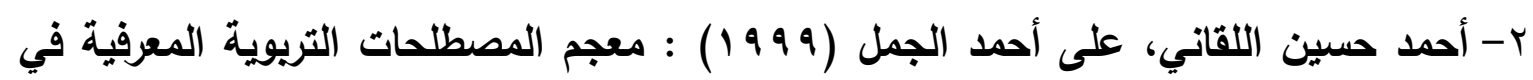

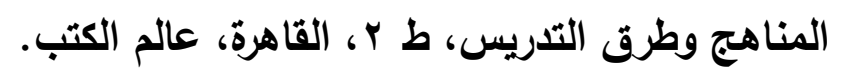

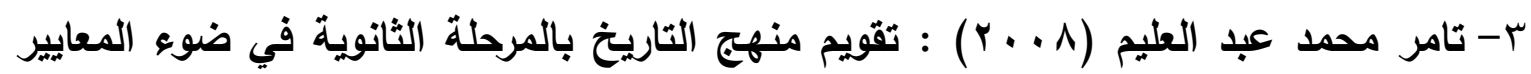
القومية وإلعالمية، رسالة ماجستير غير منشورة، كلية التربية، جامعة عين شمس.

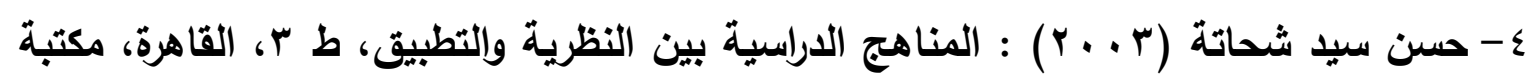
الادار العربية للكتاب.

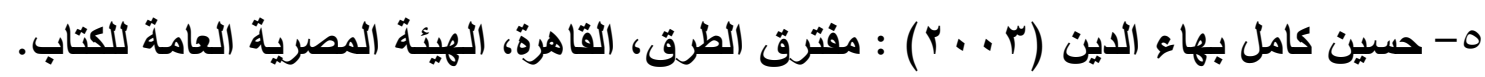

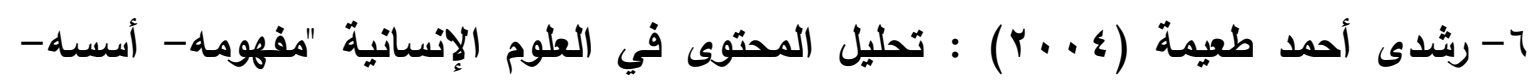

$$
\text { استخداماته"، القاهرة، دار الفكر العربي. }
$$

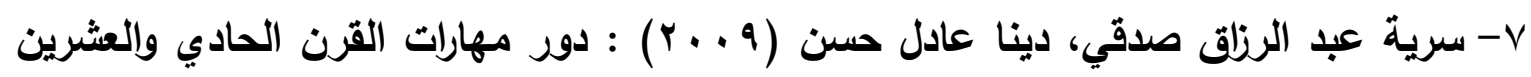

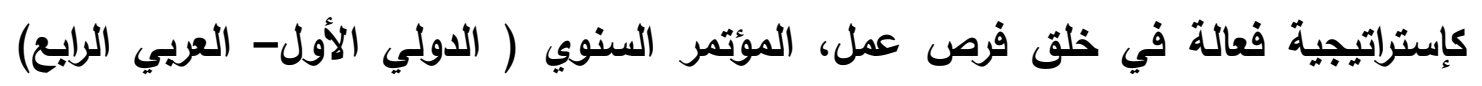

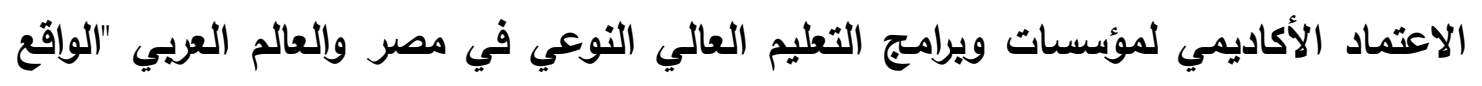

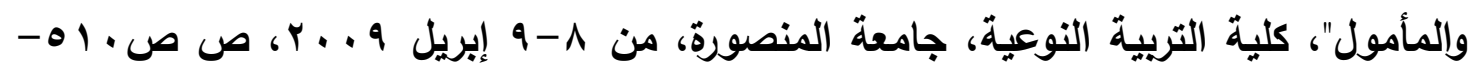
$.0 \leqslant r$

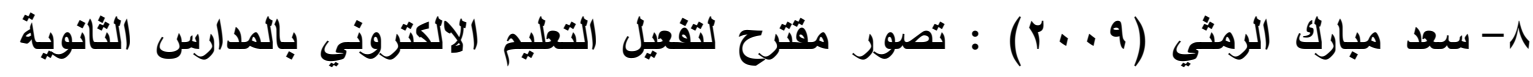

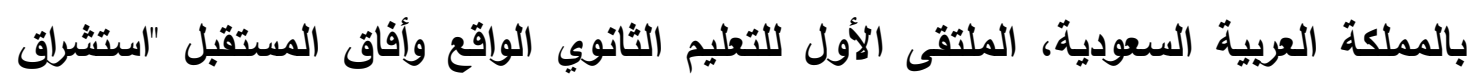

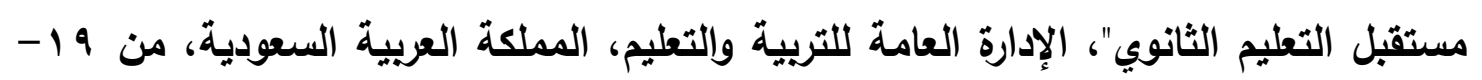

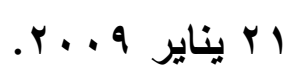

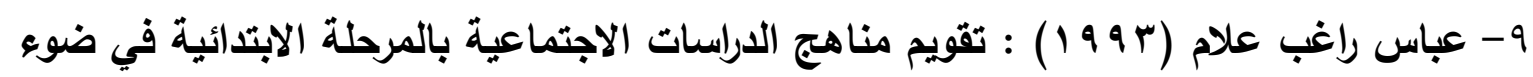
المهارات الاجتماعية، رسالة ماجستير غير منشورة، كلية التربية، جامعة المنوفية.

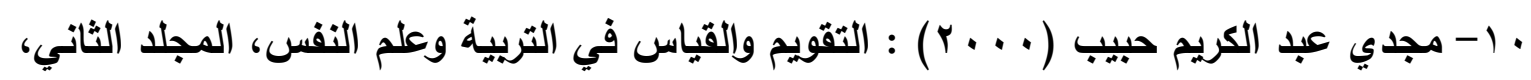
القاهرة، مكتبة النهضة المصرية.

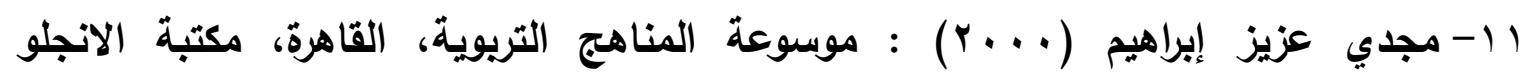
المصرية. 


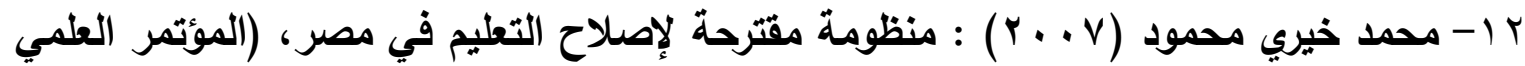
السنوي السابع) الإصلاح المؤسسي للتعليم قبل الجامعي في الوطن العربي، المركز القومي

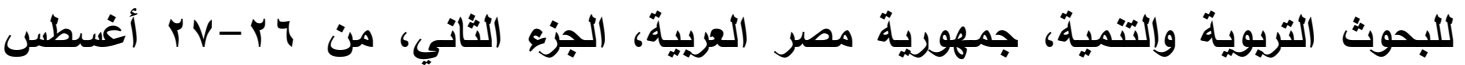
TrV

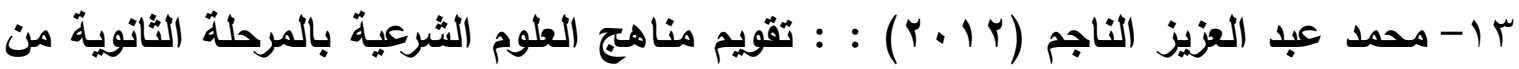
وجهة نظر المعلمين في ضوء مهارات القرن الحادي والعشرين، مجلة القراءة والمعرفة، كلية

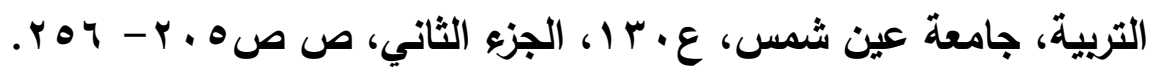

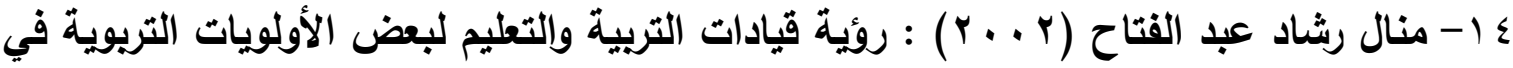

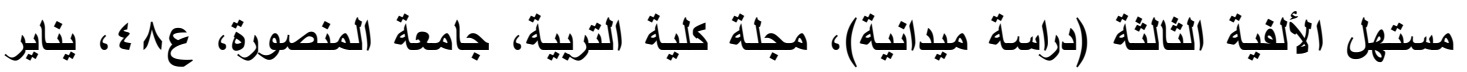

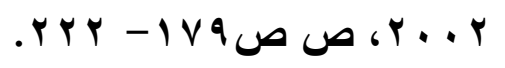

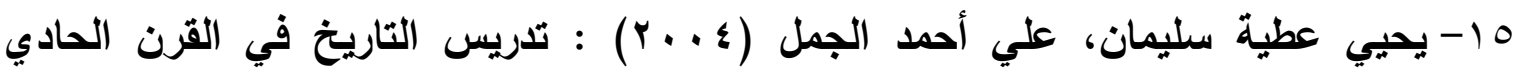

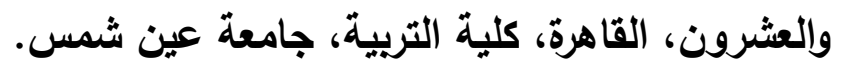
ثانياً : المراجع الأجنبية

1- Bob Regan (2008) : Why we need to teach $21^{\text {st }}$ century skills and How to do it?, JavaScript, vol. 15, no. 4, pp 10- 13, 4p.

2- Ledward, B. and Doroth, H. (2011) : An Overview of $21^{\text {st }}$ century skills, Kamehameha Schools-Research \& Evaluation.

3- Naomi Dillon (2006) : Skills for a new Century, American School Board Journal, vol. 193, no. 3, pp 22-26, 5 p.

4- Sahin, M. (2009) : Instructional design principles for $21^{\text {st }}$ century learning skills, world conference on educational science, Procedia social and Behavioral Sciences, Vol. 1, pp 1464- 1468.

5- Stephen Sawchuk (2009) : Backers of $21^{\text {st }}$ Century Skills "take flak", Education Week, vol. 28, no. 23, pp 1- 14.

6- Susan Cramer (2007) : Update your classroom with learning objects and twenty-first century skills, clearing house, vol. 80, no. 3, pp 126$132,7 p$. 